\title{
Artículos
}

\section{Territorialización del capital social: apropiación forestal comunitaria en la frontera entre Tabasco y Chiapas}

\section{Territorialization of social capital: Community forest appropriation on the border between Tabasco and Chiapas}

\author{
Mauricio Pablo Cervantes Salas ${ }^{\mathrm{a}}$ \\ Adriana Aguilar Rodríguez \\ Daniel María López López ${ }^{c}$ \\ Aristides Saavedra Guerrero ${ }^{\mathrm{d}}$
}

\section{Resumen}

Formar capital social para la apropiación colectiva favorece la conservación de los ecosistemas forestales de propiedad social. En México, la propiedad social alberga $60 \%$ de los ecosistemas forestales, y en éstos coexisten mezclas individuales y colectivas de apropiación. Mediante la acción colectiva, se estudió la organización del trabajo, los lazos de parentesco inscritos en ella y su expresión en ámbitos individuales y colectivos en cinco ejidos de Tabasco y Chiapas, con objeto de examinar la territorialización del capital social para la apropiación forestal comunitaria. Los resultados reflejan un incipiente proceso de construcción del capital social para la acción colectiva y una estructura comunitaria fragmentada.

${ }^{a}$ Centro de Investigación en Ciencias de Información Geoespacial, A.C. Dirección: Contoy 137, col. Lomas de Padierna, Tlalpan, 14240, Ciudad de México, México. Correo: mcer vantes@centrogeo.edu.mx ORCID: https://orcid.org/0000-0002-0173-2735

${ }^{\mathrm{b}}$ Centro de Investigación en Ciencias de Información Geoespacial, A.C. Correo: aaguilar@ centrogeo.edu.mx ORCID: https://orcid.org/0000-0002-6590-3222

${ }^{\mathrm{C}}$ Centro de Investigación en Ciencias de Información Geoespacial, A.C.Correo: dlopez@ centrogeo.edu.mx ORCID: https://orcid.org/0000-0003-2816-590X

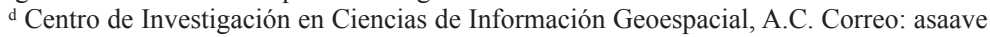
dra@centrogeo.edu.mx ORCID: https://orcid.org/0000-0003-1476-7678

Nota de los autores: Agradecemos a la Agencia para el Desarrollo Humano de la Sierra A.C., el apoyo logístico y la aplicación de cuestionarios en campo, así como a los dos dictaminadores anónimos por las observaciones hechas a este documento. El primer autor agradece al doctor Alejandro Cervantes Carson sus atinadas críticas a un primer borrador. Cualquier equívoco en este documento es plena responsabilidad del primer autor. 
Palabras clave: capital social; organización familiar del trabajo; apropiación individual; apropiación colectiva; ecosistemas forestales; ejidos.

\begin{abstract}
Forming social capital for collective appropriation encourages the conservation of socially-owned forest ecosystems. In Mexico, social ownership accounts for 60\% of forest ecosystems, in which individual and collective mixtures of appropriation coexist. Through collective action, the organization of work, the kinship ties embedded in it and their expression in individual and collective areas in five ejidos in Tabasco and Chiapas were studied, in order to examine the territorialization of social capital for community forest appropriation. The results reflect an incipient process of building social capital for collective action and a fragmented community structure.
\end{abstract}

Keywords: social capital; familiar organization of work; individual appropriation; collective appropriation; forest ecosystems; ejidos.

\title{
Introducción
}

Diversos estudios han mostrado que la formación del capital social para la apropiación colectiva de los recursos naturales genera buenos resultados para la conservación de los ecosistemas forestales (Ostrom, 2000; Chapela, 2007; Merino, 2004; Merino y Martínez, 2014; Barton, Merino y Barry, 2007; DuránMedina, Mas y Velázquez, 2007). La investigación sociológica ha dedicado importantes esfuerzos a estudiar la emergencia de los fenómenos colectivos a partir de las propiedades de las conductas individuales (Pizarro, 1998, p. 177), y ese interés, que juega un papel central en la teoría del gobierno de los bienes comunes de Elinor Ostrom, encuentra su cauce en el concepto de capital social. A través de este concepto se ha buscado conocer las condiciones que permiten que un grupo de interactuantes transite de acciones individuales a acciones colectivas orientadas al manejo y la conservación de los recursos naturales.

Considerando que en México al menos el $60 \%$ de los bosques y selvas del país están contenidos en sistemas de propiedad social (Boege, 2008; Barton, Merino y Barry, 2007), esa preocupación es especialmente importante porque en los ejidos existen ámbitos territoriales donde se promueve la apropiación individual de los recursos ejidales (parcelas y solares), y ámbitos territoriales que favorecen la apropiación colectiva para el aprovechamiento de los recursos comunes (tierras de uso común). A pesar de la extensa superficie de bosques y selvas contenidos en propiedad social -una parte importante de ellos en tierras de uso común-, en los ejidos del país sólo una quinta parte de los jefes de hogar que cuentan con algún derecho agrario 
hace uso de los recursos naturales presentes en las tierras de uso común (Patiño, 2002; Pérez-Martín del Campo, 2004; Merino y Martínez, 2014).

Aunque los regímenes de propiedad social establecen las bases territoriales de los arreglos institucionales para ejercer la apropiación colectiva de los recursos naturales (Barton, Merino y Barry, 2007, pp. 22-35), la evidencia empírica recapitulada apunta a que por sí mismos no aseguran la existencia del manejo forestal comunitario, y que en los ejidos prevalece la apropiación individual de los recursos naturales sobre la colectiva, lo que en principio podría comprometer la estabilidad ecológica de los ecosistemas forestales. Desde la perspectiva de la teoría de los bienes comunes, la apropiación colectiva es resultado y expresión del capital social, el cual se construye por la fuerza de las relaciones establecidas entre los individuos para edificar relaciones de confianza y reciprocidad, así como para alcanzar acuerdos (Ostrom y Ahn, 2003).

En vista de lo anterior, cabe preguntarse entonces, ¿cómo organizan los hogares la apropiación de los recursos naturales y cómo se expresa ésta en los ámbitos territoriales de los ejidos?, ¿prevalece la apropiación individual sobre la colectiva?, y ¿qué evidencia muestran la organización del trabajo y los ámbitos territoriales de su desarrollo con respecto a la construcción del capital social requerido para la acción colectiva?

Para dar respuesta a esas preguntas, esta investigación examinó el capital social mediante el estudio de la organización del trabajo y las relaciones familiares inscritas en ella en cinco ejidos ubicados en la frontera entre Tabasco y Chiapas, los cuales fueron seleccionados por tener ecosistemas forestales (selva alta perennifolia). Para aprehender la organización del trabajo, las relaciones familiares inscritas en ella, y la movilización del capital social en el ámbito territorial de los ejidos, se aplicaron 159 cuestionarios a los hogares, a través de los cuales se distinguieron las actividades ligadas al aprovechamiento de los recursos forestales maderables y no maderables en distintos ámbitos territoriales de sus comunidades (solares, parcelas y tierras de uso común).

Debe destacarse que este artículo deriva del informe de trabajo titulado "Manejo forestal para la sobrevivencia de los hogares fronterizos de Tabasco y Chiapas. Análisis de contexto", el cual fue liderado por el primer autor de este documento en el marco de un proyecto de alcances más amplios. ${ }^{1}$

${ }^{1}$ El proyecto se tituló "Programa de ordenamiento ecológico regional para los estados de Tabasco-Chiapas (Cuenca Grijalva-Usumacinta). Capítulo Tabasco", el cual fue realizado por el Centro de Investigación en Geografía y Geomática "Ing. Jorge L. Tamayo", A.C., para la Secretaría de Energía, Recursos Naturales y Protección Ambiental del Gobierno de Tabasco. 


\section{Marco teórico}

De acuerdo con Tarrés (1992, pp. 738-753), existen tres perspectivas generales a partir de las cuales se ha analizado la acción colectiva: la que analiza la acción tomando como referencia el sistema social; la que centra su atención en el estudio de la movilización de recursos; y la de los nuevos movimientos sociales.

Dados los objetivos centrales de este trabajo, se optó por abordar la acción colectiva como movilización de recursos retomando el marco teórico de Ostrom, ya que tal perspectiva ha centrado su atención en analizar los mecanismos de movilización del capital social para la coordinación del trabajo en torno al uso y protección de los recursos naturales. La movilización de los recursos se refiere "al conflicto entre sectores sociales producto del control de los recursos, a la lucha por transferirlos de un grupo social a otro, o de un campo de acción a otro" (Tarrés, 1992, p. 745). Esta perspectiva asume que los recursos pueden ser materiales (como el ingreso) y no materiales (redes sociales, valores compartidos, etc.), y son manejados por las personas en su vida cotidiana; estos recursos se crean, se consumen e intercambian, de manera que, en situaciones de conflicto, pueden unirse para conseguir otros recursos (Tarrés, 1992, p. 745). Uno de ellos es el capital social.

La literatura especializada en el tema se refiere al capital social como al conjunto de los recursos embebidos en una estructura social, que pueden ser accesibles y movilizados por una acción deliberada, destacando las oportunidades estructurales ofrecidas en torno al acceso y la movilización del capital social (Lin, 1982; Flap, 1991; Burt, 1982, 1997). De acuerdo con Putnam (1994, p.10) y Vergara (2010, p. 17), el capital social se refiere a lazos, normas o reglas, relaciones de confianza y mecanismos de coordinación del trabajo, que pueden ser transferidos de un arreglo social a otro para el diseño de instituciones y organizaciones en torno a la acción colectiva. Para Elinor Ostrom, el capital social es un recurso con el que cuentan los miembros de un colectivo para favorecer que el grupo de interactuantes logre cooperar dentro de un sistema en el cual los individuos están tentados a desarrollar actividades no colaborativas destinadas a maximizar los intereses individuales. ${ }^{2}$ Así, los estudios sobre el capital social tienen interés por captar las distintas formas en que se expresa la organización de las acciones colaborativas de los interactuantes.

${ }^{2}$ Ostrom cimenta su propuesta teórica a partir de las propuestas que Mancur Olson (1992) y Garret Hardin (1968) ofrecen para superar el problema de la no cooperación.

Estudios Demográficos y Urbanos, vol. 35, núm. 1 (103), enero-abril, 2020, pp. 9-50 
Para este estudio resulta relevante examinar la posibilidad de captar la movilización del capital social desde los hogares al orden de lo colectivo, mediante el análisis de la organización familiar del trabajo de las unidades domésticas ejidales. Este objetivo se sustenta en la concepción de que la familia y la propiedad de la tierra conforman la matriz institucional que alimenta las formas de organización social del trabajo. Para ello, en el primer apartado se dota de contenido conceptual a las nociones de institución, organización y capital social, y se hacen explícitas sus interrelaciones. En el segundo apartado, la propiedad de la tierra y la familia son articulados como soportes institucionales que ofrecen potencialidades para la organización y transferencia del capital social entre los espacios sociales y los ámbitos territoriales. En tal sentido, el hogar, la familia y la comunidad son tres niveles de organización del trabajo que representan espacios sociales a través de los cuales se moviliza el capital social, y como hipótesis de trabajo se asume que las especificidades de su organización en distintos ámbitos territoriales son un indicio del grado de construcción del capital social para la apropiación colectiva de los recursos naturales.

\section{Instituciones, organización y capital social}

En términos generales, las instituciones se refieren a las restricciones sociales sobre la acción de los sujetos (Portes, 2009, p. 21); es decir, son las normas o reglas acordadas o impuestas que exigen, prohíben, permiten y definen las acciones que realizan las personas (Vergara, 2010, p. 9; Schangler y Ostrom, 1992, p. 250).

Las reglas expresan derechos y obligaciones (Schangler y Ostrom, 1992, p. 250), de ahí que la importancia de las instituciones radique en la posibilidad de organizar las acciones desplegadas por los individuos. Para Ostrom, la función de las reglas en uso -usadas y supervisadas- es que se hacen cumplir una vez que los individuos eligen desarrollar esa acción (Ostrom, 2000, pp. 94-95). Las reglas prescriben derechos y obligaciones que se diseñan y anidan en distintos niveles, y pueden o no tener un correlato en los instrumentos jurídicos, tales como reglamentos, legislaciones o decisiones judiciales; en función de ese correlato, las reglas pueden ser de facto o de jure (Ostrom, 2000, pp. 94-95; Merino, 2004; Schangler y Ostrom, 1992, p. 256).

Este estudio pone especial atención a las reglas informales que sostienen al trabajo y a sus formas de organización. De acuerdo con Vergara (2010, p. 19), la organización se define como un conjunto de individuos que traba- 
jan de manera coordinada para obtener metas u objetivos compartidos por todos, siendo la división del trabajo una de sus expresiones (Vergara, 2010, p. 19). Por su parte, la estructura organizacional establece las responsabilidades jerárquicas y ordena el trabajo interno (Vergara, 2010, p. 21); es decir, la estructura organizacional responde al tipo de actividades que deben ser desarrolladas, la distribución de responsabilidades -derechos y obligacionesentre los sujetos, y las formas en las cuales deben realizarse las actividades (Vergara, 2010, p. 21), lo que implica regular los patrones internos de uso y transformación de los recursos (Schangler y Ostrom, 1992, p. 251). En ese sentido, en la organización familiar del trabajo se expresan las estructuras organizacionales más amplias y sus reglas en uso.

Como activo e inversión social, el capital social se mantiene y reproduce por situaciones de interacción continua en las que los interactuantes "desarrollan normas compartidas y patrones de reciprocidad con los que pueden construir acuerdos institucionales para resolver problemas que impiden la acción colectiva en torno al manejo de bienes de uso común" (Ostrom, 2000, p. 292). ${ }^{3}$

El capital social abarca las redes sociales y las reglas (o instituciones) formales e informales como formas de expresión específicas (Ostrom y Ahn, 2003, p. 158), y desde sus orígenes ha sido identificado como un medio que permite sincronizar las metas individuales con las metas colectivas (Coleman, 1990, pp. 314-318, citado en Ostrom y Ahn, 2003, p. 163). La construcción del capital social forma parte del proceso organizacional; es decir, de la tarea de cambiar la situación en la que los apropiadores de los recursos actúan de manera independiente, por otra situación en la que los actores ordenan y coordinan sus actividades para que la cooperación tenga mejor posibilidad de desarrollarse y sobrevivir (acción colectiva). De esa forma, una organización es el resultado de dicho proceso (Ostrom, 2000, p. 78).

${ }^{3}$ Los bienes comunes son aquellos recursos naturales caracterizados por tener cantidades finitas de unidades del recurso, de forma que el uso que hace una persona de éste, resta la cantidad de unidades de recursos disponibles para otras personas; son lo suficientemente grandes para que varios actores puedan usar simultáneamente el sistema de recursos, y los esfuerzos para excluir a terceros de los beneficios potenciales de su uso son costosos (Ostrom, 2000, p. 1). 


\section{La propiedad de la tierra y la familia: matriz institucional para la acción colectiva}

La propiedad de la tierra y la familia son dispositivos - entendidos como soporte organizacional- de la acción colectiva de los individuos porque a través de éstos se establecen derechos y obligaciones de apropiación de los bienes, se definen los sujetos en los que recaen tales prescripciones, y se ofrecen capacidades organizativas diversas para que los individuos encuentren oportunidades para resolver problemas de acción colectiva en torno a la apropiación de los recursos de uso común (RUC).

Un primer nivel de organización de las acciones de los individuos se desprende de la propiedad de la tierra. Desde una perspectiva jurídica, la propiedad aparece cuando hay derecho y Estado (Wróblewski, 1988, p. 49). Los legisperitos reconocen tres grados de apropiación: la tenencia, que es una forma precaria de ocupación de la tierra, se caracteriza por no tener ánimo alguno de retenerla o apropiársela, y su uso y disfrute no están basados en ningún título de propiedad; la posesión, que supone la intención manifiesta del poseedor de mantenerse en el uso y disfrute, y convertirse en dueño de la tierra que ocupa; finalmente, la propiedad, que incluye la posesión de la tierra y la facultad de disponer de ésta a voluntad, y está basada en un título de propiedad (Hinojosa, 1981, p. 613). Con base en los sujetos en los cuales recae el derecho, la teoría contemporánea de la propiedad reconoce tres categorías jurídicas diferenciadas de la propiedad: pública, privada y social (Álvarez, 2006, p. 7).

La propiedad pública o federal se refiere a los bienes que el Estado guarda para sí y cuyo uso o acceso está regulado por normas establecidas y vigiladas por éste (Álvarez, 2006, p. 7). La propiedad privada concede a un solo sujeto o entidad la posesión o el derecho de uso sobre un bien. Este derecho excluye a los no propietarios y da al titular del derecho de propiedad poderes amplios sobre el bien (Díaz y Díaz, 2001, citado en Álvarez, 2006, p. 7). La propiedad social, propiedad colectiva o propiedad común, corresponde a un derecho de propiedad compartido por un colectivo que excluye a otros agentes no propietarios (Álvarez, 2006, p. 7; McKean, 2000, p. 35). En México, la propiedad social se expresa en ejidos y comunidades agrarias, los cuales, de forma más general, son conocidos como unidades agrarias.

De acuerdo con McKean (2000, p. 37), los regímenes de propiedad social son dispositivos particularmente atractivos para la acción colectiva, ya que son organizaciones comunitarias preexistentes que pueden suministrar de manera más eficiente las reglas de gestión, las demandas administrativas, los mecanismos de supervisión mutua y los compromisos necesarios para 
evitar la sobreexplotación de los recursos de uso común; de esa forma, la propiedad social facilita que los colectivos pertenecientes a estos regímenes se autoorganicen para gobernar y administrar esos recursos.

No obstante, la organización de los individuos para una acción colectiva orientada a la apropiación de los recursos de uso común es compleja e incierta, y las fuentes de su incertidumbre pueden ser muy diversas (véase Ostrom, 2000, p. 70). En tal sentido, este trabajo pone atención en captar las tensiones que surgen de las estrategias de apropiación individual en contraste con las estrategias de apropiación comunitaria de recursos (Ostrom, 2000, p. 72), a través del estudio de la organización familiar del trabajo y de sus formas de expresión en distintos ámbitos territoriales.

La aproximación territorial es de gran importancia porque en la reforma agraria mexicana prevaleció una mezcla de lo individual con lo colectivo (Warman, 2001, p. 56), coexistiendo la apropiación privada y la comunitaria de los recursos naturales, las cuales pueden entrar en tensión y dominar una a la otra. Smith (2000, p. 131) apunta que se les ha prestado poca atención a estos sistemas mixtos de tenencia de la tierra.

De acuerdo con los objetivos, este trabajo adopta la definición de territorio de Jean Gottman (1952), quien, desde la geografía política, lo concibe como "el conjunto de tierras agrupadas en una unidad, que depende de una autoridad común y que goza de un determinado régimen" (Gottman, 1952, citado en Haesbaert, 2011, p. 57), “definición que pone en relieve el carácter político-administrativo del territorio a nivel estatal" (Haesbaert, 2011, p. 57), y que en este trabajo es relevante porque hace explícito el dominio del poder estatal sobre la propiedad social en México.

La vinculación del territorio con el poder sucede a diversas escalas, y la territorialidad permite hacer operativa dicha aproximación. "La territorialidad es [...] una estrategia de un individuo o grupo para alcanzar, influenciar o controlar recursos y personas a través de la delimitación y del control de áreas específicas: los territorios" (Sack, 1986, citado en Schneider y Peyré, 2006, p. 76). Esta definición, "amplia y flexible" (idem), permite hacer explícito que existen delimitaciones territoriales específicas producto de los procesos relacionales y acciones diferenciadas que dotan de atributos a los territorios en los que estos procesos y acciones se suceden, y no están exentas de las relaciones de poder. En tal sentido, la territorialización es el efecto simultáneo de las relaciones, la apropiación y los límites en los que ellos se circunscriben.

Para fines de este trabajo, distinguir las formas de organización social del trabajo, según los ámbitos territoriales privados y comunitarios, permite aprehender la "territorialización del capital social", concepto con el cual se 
busca hacer una distinción que permita analizar la movilización del capital social entre los espacios sociales (hogar, familia y comunidad) y los ámbitos territoriales (de apropiación individual -solares, parcelas-y de apropiación colectiva -tierras de uso común-).

En los ejidos de México, la Ley Agraria promueve el manejo colectivo de los recursos naturales en las tierras de uso común, donde un grupo de copropietarios, reconocidos jurídicamente como ejidatarios, se hacen cargo del diseño de las reglas, de la organización del trabajo y de la distribución de los beneficios derivados del manejo colectivo de los recursos presentes en las tierras de uso común, y tales decisiones suelen tomarse en asambleas donde únicamente ellos pueden participar (asambleas de ejidatarios). Por su parte, la apropiación individual de los recursos naturales es promovida en porciones llamadas parcelas; legalmente, cada parcela es poseída por un jefe de familia, y en ella se llevan a cabo las actividades agropecuarias destinadas a la subsistencia familiar (a quienes tienen la titularidad de estos derechos agrarios se les conoce como ejidatarios o posesionarios). Finalmente, también existe el reconocimiento de los derechos de propiedad sobre un solar, es decir, una extensión de tierra que conforma las zonas urbanas en las que se construyen las viviendas de los habitantes; la titularidad de los derechos de los solares recae en ejidatarios, posesionarios y avecindados (véase Warman, 2001).

A su vez, la familia es un dispositivo de la organización de la acción colectiva porque en ella se procesan las oportunidades diferenciales de los individuos respecto al acceso a los recursos, de acuerdo con las características socioeconómicas, demográficas y culturales de sus miembros y de la unidad doméstica de pertenencia (Welti y Rodríguez, 1997, citado en Baca 2002, p. 201; Camarena, 2003). De esa forma, la familia es un espacio de mediación a través del cual la organización del trabajo entre sus miembros $\mathrm{y}$ los beneficios derivados de ello responden a reglas cambiantes que pueden reflejar el poder relativo de las partes en conflicto (Gimble, 1991, citado en Fernández-Huerga, 2010, p. 117). De esa forma, la familia, como institución, contribuye a la producción de la heterogeneidad, segmentación y desigualdad con base en oportunidades diferenciales de acceso a los recursos, conforme a la edad, el sexo, la relación de parentesco, la raza y los ámbitos de interacción social (véase Fernández-Huerga, 2010; Baca, 2002; Rau, 2006).

Debe aclararse que no es necesario formar parte del mismo hogar para formar parte de la familia (Torres, Ortega, Garrido y Reyes, 2008, p. 31); es decir, existe una dinámica familiar que implica relaciones de cooperación, intercambio, poder y conflicto (De Oliveira y Ariza, 1999, p. 230; Torres, Ortega, Garrido y Reyes, 2008, p. 33) que superan el ámbito de la vivienda 
y están mediadas por las relaciones de parentesco. En tal sentido, mediante el uso del concepto de hogar se pueden distinguir las relaciones que suceden dentro o fuera del ámbito doméstico. Específicamente, el hogar se refiere a un individuo o grupo de personas que comparten o no relaciones de parentesco, habitan en una misma vivienda y comparten alimentos y gastos (Lira, 1975; Tuirán, 1996; De Oliveira y Ariza, 1999).

Así, las redes de parentesco familiar forman parte del capital social con el que cuenta el hogar para la movilización de recursos, y de acuerdo con Portales (2013, p. 5), el capital social de un hogar es producto de las relaciones sociales que los miembros del hogar tienen por pertenecer a una determinada red social, la cual les da acceso a algún tipo de recurso -tangible o intangible- o capital. Captar el hogar y la familia como ámbitos diferenciados y conectados para estudiar la organización del trabajo, e incorporar a ello la dimensión territorial en la que se expresan sus formas de asociación, permite analizar en qué ámbitos territoriales los miembros del hogar actúan de manera independiente y en cuáles surge la cooperación en torno al manejo de los recursos naturales. De esa forma, la "territorialización del capital social" analiza la organización familiar del trabajo en los distintos ámbitos territoriales de los ejidos como una expresión de la relación entre los actores, la estructura institucional que soporta la apropiación de los recursos naturales y las delimitaciones territoriales en las que ello se circunscribe.

\section{Estrategia metodológica}

El trabajo de campo se realizó a finales de mayo y principios de junio de 2015, y tuvo por objetivo conocer cómo los hogares organizan la apropiación de los recursos forestales maderables y no maderables, según las relaciones de propiedad que guardan las unidades domésticas con los distintos ámbitos territoriales de los ejidos ubicados en la frontera entre Tabasco y Chiapas. La estrategia metodológica se compuso de tres etapas: la selección de los casos de estudio, el diseño de los cuestionarios a hogares y su aplicación, y finalmente, la recopilación de la información.

Respecto a la selección de los casos de estudio, mediante entrevistas a informantes clave se identificaron cinco ejidos de la región de Tabasco y Chiapas donde hubiera condiciones de seguridad para poder desarrollar el trabajo de campo, ${ }^{4} \mathrm{y}$ además existieran ecosistemas forestales. A través del

${ }^{4}$ Los criterios empleados para identificar las condiciones de inseguridad en campo fueron la existencia de conflictos en el interior de los ejidos y la presencia de la delincuencia organizada. 
uso de imágenes Spot (con 1.5 metros de resolución espacial y referidas al año 2014), se analizó la cobertura vegetal y el uso de suelo para identificar la diversificación productiva, así como la presencia y tipo de ecosistemas forestales presentes en la región. En el Mapa 1 se muestran de manera sucinta los usos de suelo de los cinco ejidos seleccionados y sus características generales . ${ }^{5}$

Por su parte, el diseño del cuestionario a los hogares tuvo como principal objetivo aprehender las formas de organización del trabajo facilitado por el capital social (Ostrom y Ahn, 2003, p. 174), y fue aplicado a un total de 159 unidades domésticas. Este cuestionario captó la red de relaciones sociales establecidas entre los miembros del hogar en torno a las actividades ligadas al aprovechamiento forestal maderable y no maderable, entendiendo que tales relaciones son una expresión cuantificable de las diversas configuraciones que puede adoptar el capital social.

Dado que muchos de los problemas de la acción colectiva están incrustados en otras formas de organización preexistentes (Ostrom y Ahn, 2003, p. 180), el diseño del cuestionario puso especial atención en captar cómo las relaciones de propiedad con la tierra (ejidatario, posesionario o avecindado) y la estructura organizacional preexistente (hogar, familia y comunidad) ordenan el trabajo, y así lograr captar el funcionamiento general de las instituciones locales, entendidas éstas como las "reglas puestas en práctica en contextos particulares" (Merino, 2004, p. 128).

También fue necesario incluir una noción amplia del concepto de trabajo que fuera más allá del empleo remunerado, y así poder incluir al análisis los ámbitos doméstico y extradoméstico para captar la mayor diversidad posible de las actividades o tareas que aportan a la satisfacción de las necesidades del hogar. Esta perspectiva de análisis retoma lo señalado por Tapinos (1994, p. 70) acerca de la "dualidad de la variable demográfica", donde el individuo es a la vez productor y consumidor, aseveración que la perspectiva de las estrategias familiares de vida ha llevado a nivel de hogar y que, en la tradición sociodemográfica, se ha abordado para analizar una gran variedad de comportamientos sociales, económicos y demográficos que hacen aportaciones a la reproducción del grupo doméstico, teniendo como principio que el hogar es un espacio social en el que a la vez se organizan el consumo y la producción (véase Torrado, 1981, 2003; De Oliveira y Ariza, 1999; Tuirán, 1996; Cortés, 1990).

${ }^{5}$ Los datos sobre los usos de suelo descritos son producto de la investigación realizada por Saavedra, López y Castellanos, 2015. 


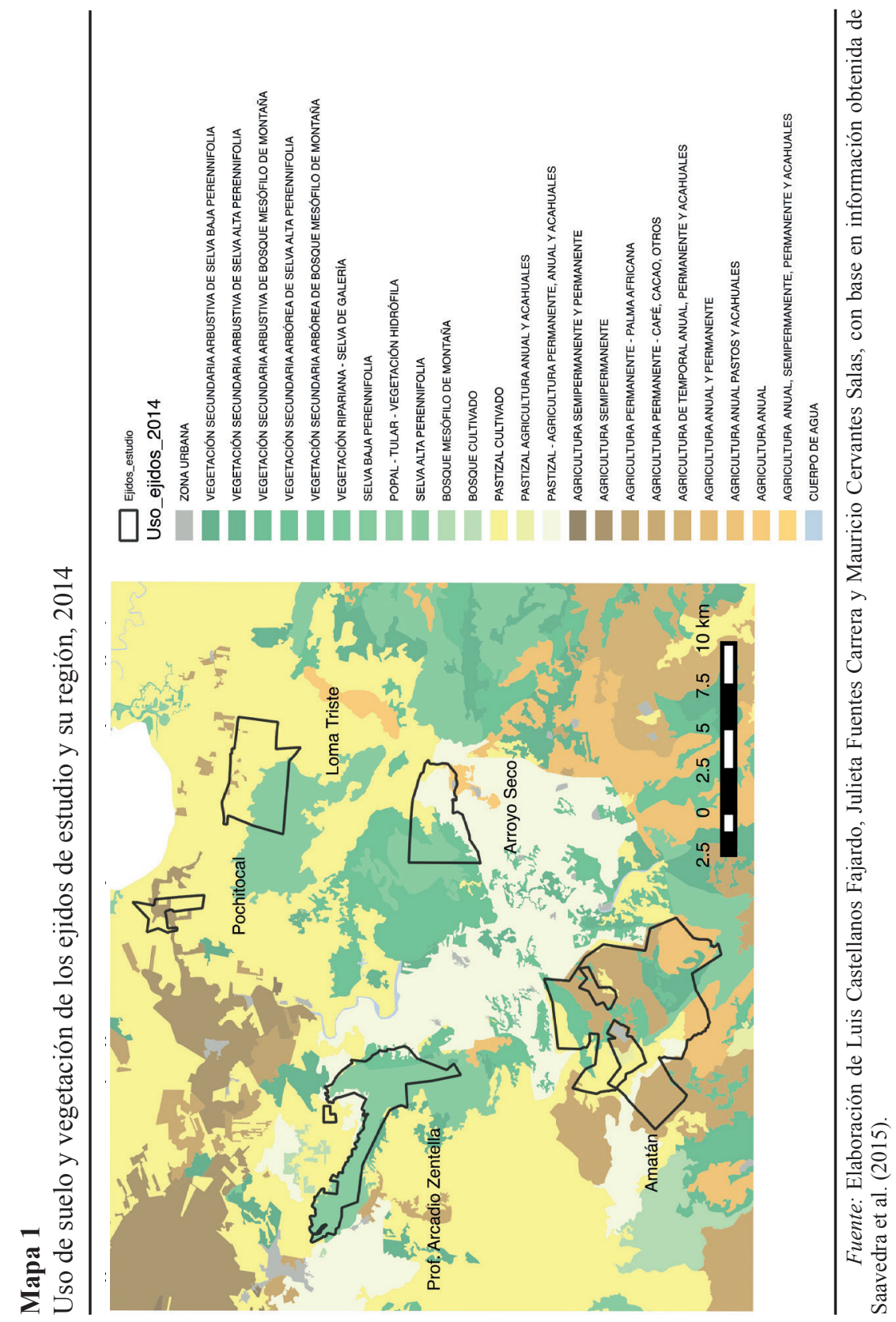


Para conocer la estructura organizacional del trabajo, se aplicaron preguntas sobre las relaciones de parentesco y la posición en el trabajo. La relativa a las relaciones de parentesco permitió averiguar cómo movilizan los hogares el capital social, mientras que la referente a la posición en el trabajo posibilitó captar tanto la relación de propiedad del trabajador con la unidad de producción, como la naturaleza de la relación con otros trabajadores. A través de dichas variables se indagaron las relaciones de cooperación e intercambio asociadas a las actividades que desarrollan los miembros del hogar. Para averiguar la posición en el trabajo se emplearon las categorías usadas por el Censo de Población 2010 de México (véase INEGI, 2010).

Debe señalarse que las fuentes de información sociodemográfica en el país normalmente no registran la gran diversidad de formas de organización del trabajo en propiedad social; tampoco suelen dar cuenta de las múltiples formas de acceso, posesión y tenencia de la tierra que existen en los contextos agrarios. Por ello, el cuestionario incluyó categorías de respuesta que permitieron captar el trabajo colectivo (trabajador con o sin pago en colaboración con otros ejidatarios o comuneros) y los tratos agrarios que comúnmente se desarrollan en las parcelas y tierras de uso común en los ejidos. ${ }^{6}$ De las distintas formas de expresión empírica de este concepto, el cuestionario puso especial interés en registrar la aparcería o mediería y la asociación. ${ }^{7}$

De esa forma, las relaciones de parentesco y la situación laboral fueron las dos categorías analíticas empleadas para conocer los componentes del capital social que nos interesa analizar: la movilización de recursos y la naturaleza de las relaciones establecidas.

Las categorías empleadas para captar las actividades ligadas al aprovechamiento de los recursos forestales maderables y no maderables usaron como base los términos empleados por la Ley de Desarrollo Forestal Sustentable (artículo 7, numerales XXVIII y XXIX). ${ }^{8}$ Por su parte, para aproxi-

6 "Los tratos agrarios son las relaciones que los sujetos agrarios establecen al interior de los ejidos o comunidades [...] que tienen un carácter de acuerdo entre los ejidatarios o propietarios de la tierra y de éstos con otros individuos al interior de la familia o fuera de ella para poseer o explotar la tierra" (Robles, 2005, p. 27).

7 De acuerdo con Leigh (2007, pp. 168-169), las modificaciones realizadas a la Ley Agraria Mexicana en 1992 (específicamente al artículo 105) permitieron la presencia de socios, los cuales representan subgrupos de trabajo para el aprovechamiento de los recursos comunes. Sin embargo, tomando en cuenta que los bosques de las tierras de uso común no pueden ser subdivididos físicamente, la ley no es clara respecto a cómo puede ser organizada la apropiación de los bosques, lo que ofrece espacio para ensayar entre el control individual y el control colectivo de los recursos naturales.

${ }^{8}$ De acuerdo con esta ley, los recursos forestales maderables son los "constituidos por vegetación leñosa susceptibles de aprovechamiento o uso", mientras que los recursos forestales

Estudios Demográficos y Urbanos, vol. 35, núm. 1 (103), enero-abril, 2020, pp. 9-50 
marse al grado de institucionalización del aprovechamiento forestal maderable, las opciones de respuesta permitieron distinguir el aprovechamiento desarrollado con o sin plan de manejo forestal.

Los temas incluidos en el cuestionario fueron las características socioeconómicas y demográficas de los individuos (edad, sexo, relación de parentesco, nivel de escolaridad, alfabetismo, actividades económicas, ocupación, situación laboral e ingresos), y se identificaron los ámbitos territoriales en los que suceden las actividades desarrolladas (parcela, solar y tierras de uso común). Tales actividades fueron captadas para todos los miembros del hogar a partir de los ocho años cumplidos, principalmente porque en las zonas rurales las tareas domésticas y extradomésticas se desarrollan desde edades muy tempranas. El periodo de referencia empleado para indagar las actividades económicas fue de un año (2014).

Finalmente, el contenido del cuestionario fue validado mediante una prueba piloto aplicada en tres comunidades que contaban con grados contrastantes de diversificación productiva. ${ }^{9}$

El levantamiento de los cuestionarios en campo estuvo a cargo de un grupo de tres personas que recibieron capacitación, con la cual se familiarizaron con la estructura del cuestionario, los conceptos, las preguntas, las categorías de análisis, las unidades de observación y su aplicación. Para la captura de la información en campo se desarrolló una aplicación que permitió subir el cuestionario en dispositivos móviles asociados a una base de datos. El desarrollo de la aplicación incluyó filtros por edad y sexo, impidiendo el registro erróneo de información, lo cual permitió mantener la coherencia interna de los datos y evitó la necesidad de tener supervisores en campo. ${ }^{10}$

Para captar la relación de los derechos de propiedad con los ámbitos territoriales de movilización del capital social, los cuestionarios se aplicaron a hogares ejidatarios, posesionarios y avecindados. Un hogar ejidatario quedó definido como la unidad doméstica donde al menos uno de sus miembros es ejidatario. El hogar posesionario se asumió como el que al menos tiene un posesionario y no hay ejidatarios. El hogar avecindado es aquel

no maderables "son la parte no leñosa de la vegetación de un ecosistema forestal, y son susceptibles de aprovechamiento o uso, incluyendo líquenes, musgos, hongos y resinas, así como los suelos de terrenos forestales y preferentemente forestales".

${ }^{9}$ Las comunidades en las cuales se aplicó la prueba piloto se localizan en el municipio de Tacotalpa, Tabasco: una comunidad dedicada a actividades forestales, otra destinada a actividades agrícolas y agropecuarias, y una más con actividades agrícolas, forestales y agropecuarias (ejido Poaná, ejido Zunú y Patastal, y $5^{\text {a }}$ sección del ejido Cerro Blanco).

${ }^{10}$ Finalmente, la información captada en los dispositivos móviles fue descargada a bases de datos por vía remota y almacenada en servidores de internet. 
donde al menos uno de sus miembros es avecindado y no hay ejidatarios ni posesionarios. En las viviendas con más de un hogar, el cuestionario fue aplicado a sólo uno de ellos.

De esa forma, el método de muestreo empleado en este trabajo fue de tipo intencional, y la aplicación de los cuestionarios a hogares ejidatarios, posesionarios y avecindados se sustentó en el criterio de saturación teórica (Ruiz, 2003). Así, entre mayo y junio de 2015, mediante el método de muestreo bola de nieve, se aplicaron 76 cuestionarios a hogares de avecindados, 68 cuestionarios a hogares ejidatarios y 15 cuestionarios a hogares posesionarios, recopilando información para un total de 159 hogares y 746 personas, en un lapso de 15 días (Cuadro 1). ${ }^{11}$

Los datos fueron examinados para el conjunto de las cinco comunidades, por lo que su interpretación corresponde a un análisis de corte regional. Debe aclararse que esta aproximación es de corte cualitativo y en el orden de lo exploratorio, de forma que los resultados sólo son representativos para el universo de hogares al que se aplicó este cuestionario. Congruente con ello, los resultados que se presentan a continuación son una primera aproximación para analizar cómo los hogares y sus miembros, de acuerdo con los derechos agrarios del jefe del hogar (ejidatario, posesionario y avecindado), articulan las acciones individuales y colectivas, y cómo cambia dicha articulación en los solares, las parcelas y las tierras de uso común. Es decir, tiene como principal objetivo dotar de contenido empírico al concepto que este trabajo acuña: la territorialización del capital social, con el objetivo de ser empleado para identificar la expresión territorial de los procesos asociados a la construcción del capital social comunitario.

\section{Resultados}

La participación laboral en las tierras de uso común, las parcelas y los solares fueron captadas para un universo de 626 personas de ocho años y más. En los hogares ejidatarios se incluyó un total de 303 personas de ocho años y más; en los hogares avecindados se alcanzó un universo de 268 personas;

11 En un principio, en cada ejido se tuvo por objetivo aplicar 15 cuestionarios a hogares de ejidatarios, 15 a posesionarios y 15 más a avecindados. Como se aprecia en el Cuadro 1, el número de cuestionarios aplicados tiene una alta variabilidad entre comunidades, lo cual se debe, por una parte, al limitado número de sujetos agrarios residentes en esas comunidades, y por otra, a la escasa actualización de datos por parte del Registro Agrario Nacional. Finalmente, tales discrepancias también se relacionan con el hecho de que las reglas de facto a nivel local pueden o no reconocer a estos sujetos agrarios, más allá de su correlato en documentos oficiales. 


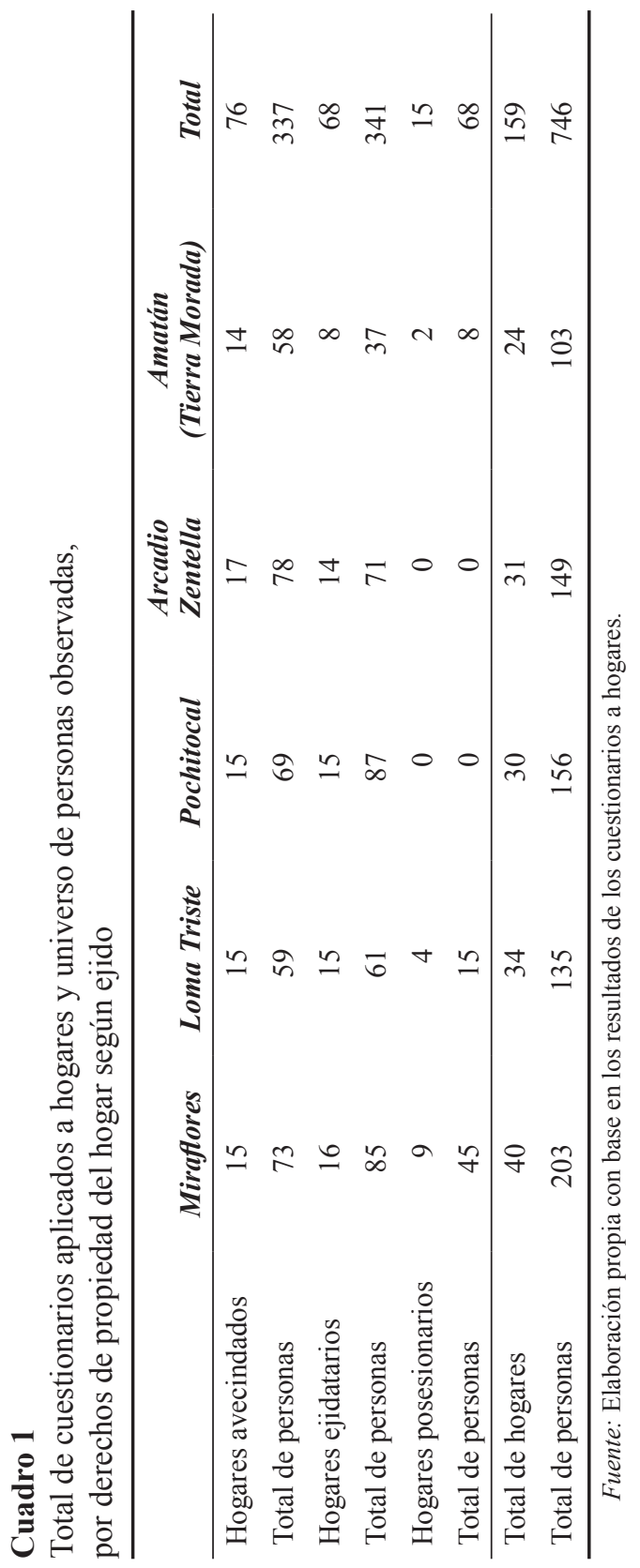


y en los hogares posesionarios, a 57 personas. Los totales mostrados en los cuadros subsecuentes son menores a este universo, y ello se debe a los no especificados.

En las tierras de uso común, el porcentaje de no especificados de los ejidatarios fue $3.96 \%$ (equivalente a 12 personas), en los avecindados de $0.82 \%$ (equivalente a tres personas) y en los posesionarios de $12.28 \%$ (equivalente a siete personas). En las parcelas, el porcentaje de no especificados de los ejidatarios fue $5.6 \%$ (equivalente a 17 personas), en los avecindados fue $2.24 \%$ (equivalente a seis personas), y en los posesionarios el $14 \%$ (equivalente a ocho personas). En los solares, el porcentaje de no especificados de los ejidatarios fue $1.65 \%$ (cinco personas), en los avecindados de $1.87 \%$ (cinco personas) y en los posesionarios $12.28 \%$ (siete personas). Los bajos porcentajes de no especificados dan muestra de la buena calidad de los datos obtenidos respecto a la participación laboral en los ámbitos territoriales analizados, aunque las dificultades para captar esta información fueron mayores en los hogares posesionarios.

\section{Tierras de uso común}

Las actividades desarrolladas en las tierras de uso común son la siembra de hortalizas, arroz, frijol, chile, sandía, calabaza, yuca y plátano, así como el aprovechamiento de recursos forestales maderables y la colecta de recursos forestales no maderables (recolecta de leña, hongos, suelo de monte o aprovechamiento de resinas y recolecta de plantas medicinales).

Para el conjunto de los cinco ejidos, los datos indican que el número de personas de ocho años y más que desarrollaron algún trabajo en las tierras de uso común fue marginal. Durante 2014, de un total de 606 personas, únicamente $9.9 \%$ (equivalente a 60 personas) desarrolló algún trabajo en esas tierras (Cuadro 2). Respecto a los hogares ejidatarios, el 17.9\% de los miembros del hogar declaró haber realizado alguna actividad económica en las tierras de uso común (equivalente a 52 personas). Por su parte, la participación laboral de los miembros de hogares posesionarios y avecindados es prácticamente nula: el $2 \%$ de personas pertenecientes a hogares posesionarios (equivalente a una persona) declaró haber desarrollado alguna actividad, y en hogares avecindados fue del $2.6 \%$ (equivalente a siete personas).

En términos generales, quienes más participan en las actividades económicas son los jefes/as de hogar, con una proporción del 55\%, seguido de los hijos/as, quienes representaron el 30\% del total, y finalmente el esposo/a, 


\section{Cuadro 2}

Número de personas que durante el año 2014 trabajaron en las tierras de uso común, por relación de parentesco con el jefe del hogar según derechos de propiedad del hogar

\begin{tabular}{|c|c|c|c|c|c|c|}
\hline \multirow[b]{2}{*}{$\begin{array}{l}\text { Relación } \\
\text { de parentesco }\end{array}$} & \multicolumn{6}{|c|}{ Ejidatario } \\
\hline & Participa & $\%$ & $\begin{array}{c}\text { No } \\
\text { participa }\end{array}$ & $\%$ & Total & $\%$ \\
\hline Total & 52 & 100.0 & 239 & 100.0 & 291 & 100.0 \\
\hline $\mathrm{Jefe} / \mathrm{a}$ & 28 & 53.8 & 39 & 16.3 & 67 & 23.0 \\
\hline Esposo/a & 5 & 9.6 & 58 & 24.3 & 63 & 21.6 \\
\hline Hijo/a & 15 & 28.8 & 103 & 43.1 & 118 & 40.5 \\
\hline Nieto/a & 2 & 3.8 & 18 & 7.5 & 20 & 6.9 \\
\hline Padre o madre & 1 & 1.9 & 3 & 1.3 & 4 & 1.4 \\
\hline Otro parentesco & 1 & 1.9 & 18 & 7.5 & 19 & 6.5 \\
\hline \multirow[t]{2}{*}{ Total } & 52 & 17.9 & 239 & 82.1 & 291 & 100.0 \\
\hline & \multicolumn{6}{|c|}{ Avecindado } \\
\hline $\begin{array}{l}\text { Relación } \\
\text { de parentesco }\end{array}$ & Participa & $\%$ & $\begin{array}{c}\text { No } \\
\text { participa } \\
\end{array}$ & $\%$ & Total & $\%$ \\
\hline Total & 7 & 100.0 & 258 & 100.0 & 265 & 100.0 \\
\hline Jefe/a & 4 & 57.1 & 72 & 27.9 & 76 & 28.7 \\
\hline Esposo/a & 0 & 0.0 & 68 & 26.4 & 68 & 25.7 \\
\hline $\mathrm{Hijo} / \mathrm{a}$ & 3 & 42.9 & 94 & 36.4 & 97 & 36.6 \\
\hline Nieto/a & 0 & 0.0 & 12 & 4.7 & 12 & 4.5 \\
\hline Padre o madre & 0 & 0.0 & 6 & 2.3 & 6 & 2.3 \\
\hline Otro parentesco & 0 & 0.0 & 6 & 2.3 & 6 & 2.3 \\
\hline \multirow[t]{2}{*}{ Total } & 7 & 2.6 & 258 & 97.4 & 265 & 100.0 \\
\hline & \multicolumn{6}{|c|}{ Posesionario } \\
\hline $\begin{array}{l}\text { Relación } \\
\text { de parentesco }\end{array}$ & Participa & $\%$ & $\begin{array}{c}\text { No } \\
\text { participa }\end{array}$ & $\%$ & Total & $\%$ \\
\hline Total & 1 & 100.0 & 49 & 100.0 & 50 & 100.0 \\
\hline Jefe/a & 1 & 100.0 & 13 & 26.5 & 14 & 28.0 \\
\hline Esposo/a & 0 & 0 & 11 & 22.4 & 11 & 22.0 \\
\hline $\mathrm{Hijo/a}$ & 0 & 0 & 23 & 46.9 & 23 & 46.0 \\
\hline Nieto/a & 0 & 0 & 0 & 0.0 & 0 & 0.0 \\
\hline Padre o madre & 0 & 0 & 0 & 0.0 & 0 & 0.0 \\
\hline Otro parentesco & 0 & 0 & 2 & 4.1 & 2 & 4.0 \\
\hline Total & 1 & 2.0 & 49 & 98.0 & 50 & 100.0 \\
\hline
\end{tabular}




\begin{tabular}{|c|c|c|c|c|c|c|}
\hline \multirow[b]{2}{*}{$\begin{array}{l}\text { Relación } \\
\text { de parentesco }\end{array}$} & \multicolumn{6}{|c|}{ Total } \\
\hline & Participa & $\%$ & $\begin{array}{c}\text { No } \\
\text { participa }\end{array}$ & $\%$ & Total & $\%$ \\
\hline Total & 60 & 100.0 & 546 & 100.0 & 606 & 100.0 \\
\hline Jefe/a & 33 & 55.0 & 124 & 22.7 & 157 & 25.9 \\
\hline Esposo/a & 5 & 8.3 & 137 & 25.1 & 142 & 23.4 \\
\hline $\mathrm{Hijo/a}$ & 18 & 30.0 & 220 & 40.3 & 238 & 39.3 \\
\hline Nieto/a & 2 & 3.3 & 30 & 5.5 & 32 & 5.3 \\
\hline Padre o madre & 1 & 1.7 & 9 & 1.6 & 10 & 1.7 \\
\hline Otro parentesco & 1 & 1.7 & 26 & 4.8 & 27 & 4.5 \\
\hline Total & 60 & 9.9 & 546 & 90.1 & 606 & 100.0 \\
\hline
\end{tabular}

Fuente: Elaboración propia con base en los resultados de los cuestionarios a hogares.

con el 8.3\% (Cuadro 2). En el interior de los hogares ejidatarios ese patrón se reproduce consistentemente. En los hogares avecindados únicamente los jefes/as de hogar e hijos/as participan en las tierras de uso común, y en los hogares posesionarios sólo participó un jefe de hogar.

La actividad en la que más personas participaron fue la agricultura (55 personas), seguida de las forestales no maderables (31 personas), las pecuarias (seis personas) y las forestales maderables sin plan de manejo (cinco personas). En promedio, cada una de las 60 personas realizó 1.5 actividades (Cuadro 3).

La mayor parte de las personas coordinan las actividades con un familiar, ya sea como trabajadores familiares sin pago $(50.8 \%)$, o bien por cuenta propia (37.7\%) (Cuadro 4). En los hogares avecindados -hogares que no tienen derechos de propiedad sobre las tierras de uso común-, ser un trabajador familiar sin pago significa que las actividades realizadas en tierras de uso común se organizan por intermedio de un hogar ejidatario o posesionario, lo que indica la importancia de la red de relaciones que ofrecen el hogar y la familia para acceder a las tierras de uso común. Destaca que ninguna persona declaró llevar a cabo actividades como trabajador en colaboración con otros ejidatarios (con o sin pago), corroborando de esa forma que en estos ejidos no existe un manejo colectivo de los recursos maderables y no maderables en las tierras de uso común. No obstante, un avecindado declaró desarrollar actividades en las tierras de uso común como socio. 


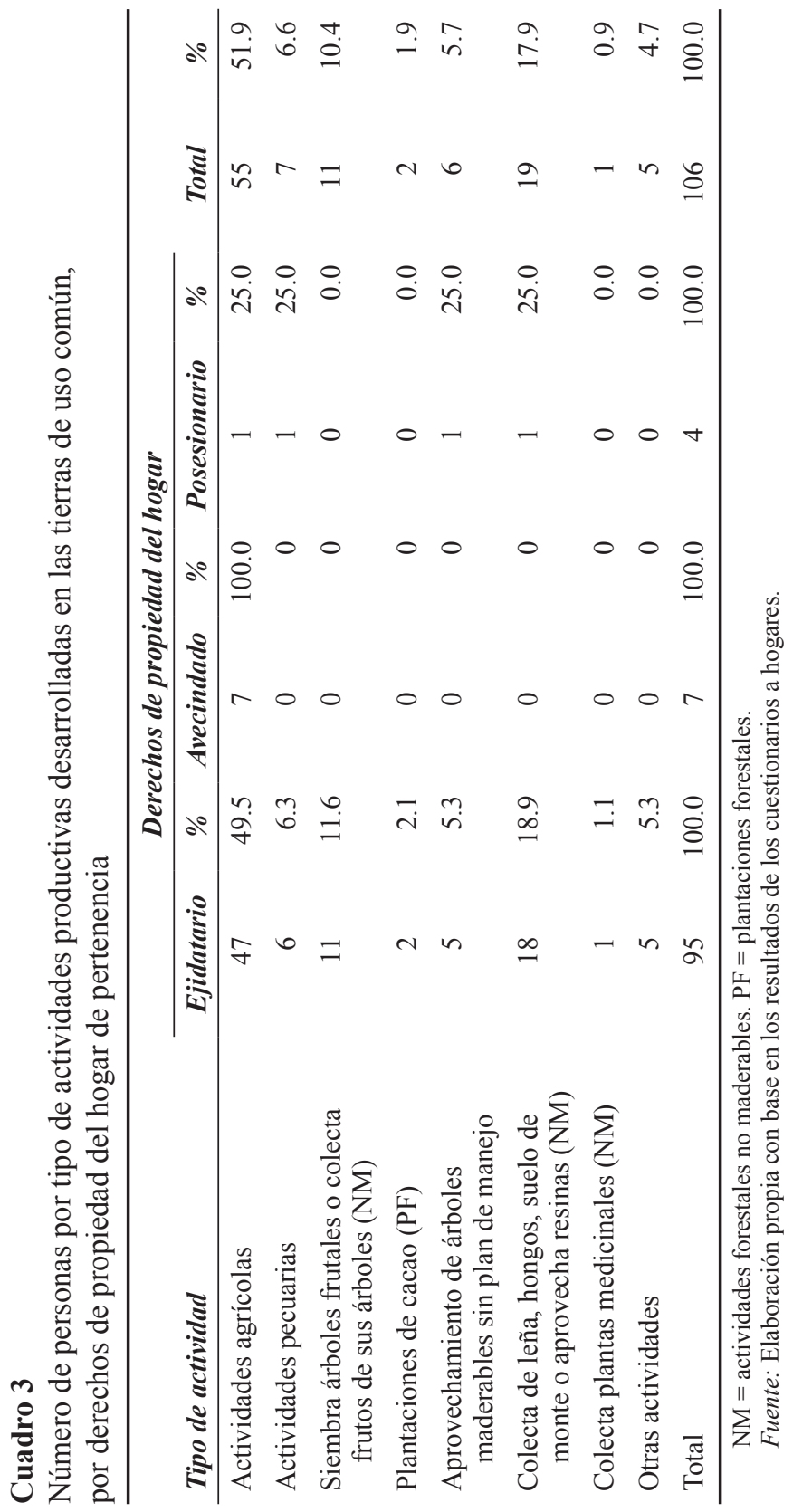




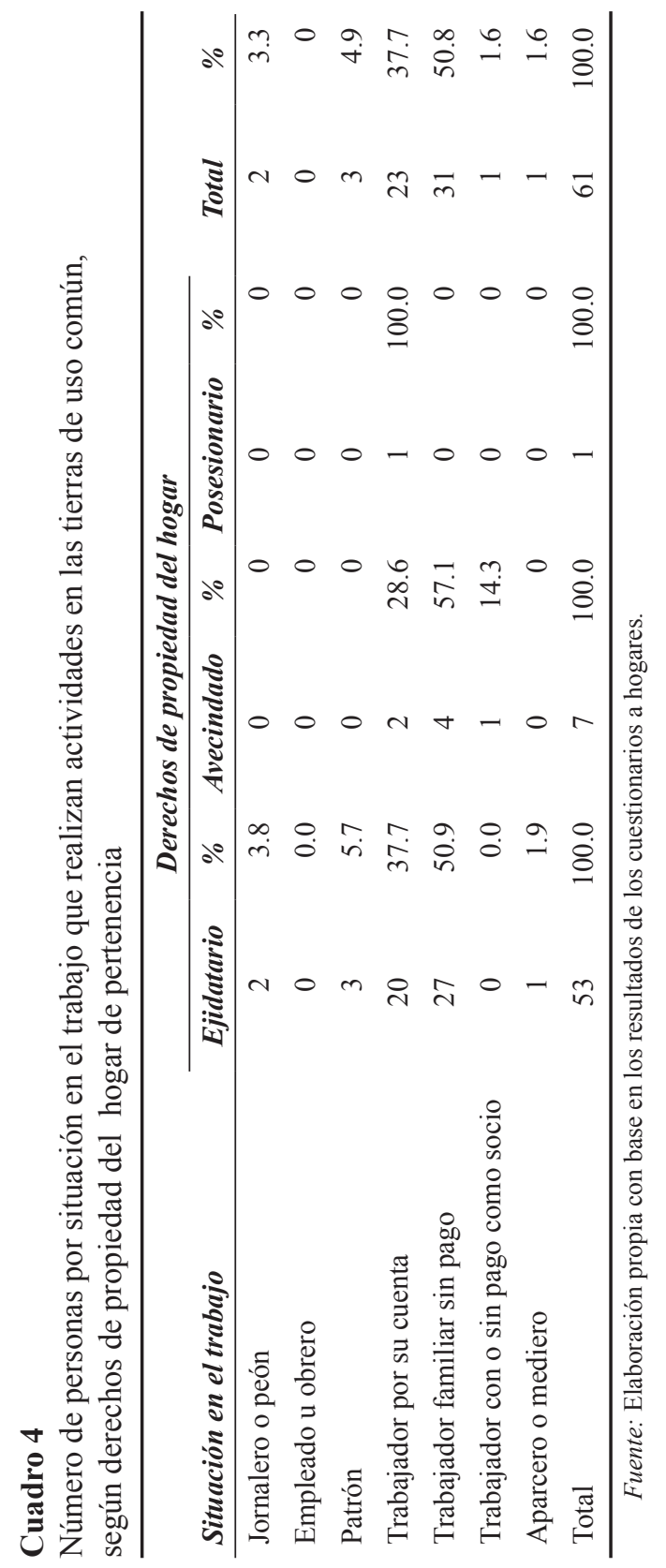




\section{Tierras parceladas}

En las tierras parceladas se desarrolla una gran diversidad de actividades: cultivo de café, plátano, frijol y arroz, aprovechamiento del cacao, cría de ganado, labores forestales maderables y no maderables, así como plantaciones forestales comerciales (teca, melina o palma africana).

La participación de los miembros del hogar es muy alta, ya que del total de personas de ocho años y más en las que se pudo captar la partición en las actividades de las parcelas (597 personas), el 34\% declaró haber participado durante el año de referencia (equivalente a 203 personas) (Cuadro 5).

En términos generales, los miembros del hogar que más se incorporaron a esas actividades fueron los jefes de hogar (50.2\%), los hijos/as (37.4\%) y el esposo/a (10.3\%). Destaca que en los hogares posesionarios no se captó la participación del cónyuge, pero la de los hijos tuvo un peso relativo considerablemente mayor al alcanzado en los hogares ejidatarios y los avecindados. En estos últimos hogares, en contraparte, sí se registró la participación del cónyuge.

Las actividades que acumulan mayor participación de personas son las agrícolas (166 personas), el aprovechamiento de los recursos forestales no maderables (136 personas) y las actividades pecuarias (65 personas) (Cuadro 6). El aprovechamiento de árboles maderables sin un plan de manejo fue desarrollado por un total de 54 personas, y 22 declararon trabajar en plantaciones forestales comerciales (en siembra de teca, melina, palma africana, o en las plantaciones de cacao).

Las actividades en las que más participan los miembros de hogares ejidatarios son las forestales no maderables (76 personas), seguido de las agrícolas ( 75 personas) y las pecuarias (51 personas). Un total de 23 personas declararon realizar aprovechamiento forestal maderable sin plan de manejo, tres más manifestaron tener plantaciones forestales (teca, melina o palma africana) y otras siete personas aprovechar el cacao (Cuadro 6).

Los miembros de los hogares avecindados se incorporaron con mayor frecuencia a las actividades agrícolas (64 personas), al aprovechamiento de los recursos forestales no maderables (42 personas) y a las actividades pecuarias (11 personas). En los hogares posesionarios se desarrollaron con mayor frecuencia las actividades agrícolas (27 personas) y el aprovechamiento de recursos forestales no maderables (18 personas), mientras que sólo cuatro personas aprovecharon los árboles forestales maderables sin plan de manejo y tres más realizaron actividades pecuarias (Cuadro 6).

La situación laboral que guardan los miembros de los hogares ejidatarios, avecindados y posesionarios en las actividades desarrolladas dentro de las 


\section{Cuadro 5}

Número de personas que durante 2014 trabajaron en las parcelas, por relación de parentesco con el jefe del hogar según derechos de propiedad del hogar

\begin{tabular}{|c|c|c|c|c|c|c|}
\hline \multirow[b]{2}{*}{$\begin{array}{l}\text { Relación } \\
\text { de parentesco }\end{array}$} & \multicolumn{6}{|c|}{ Ejidatario } \\
\hline & Participa & $\%$ & $\begin{array}{c}\text { No } \\
\text { participa }\end{array}$ & $\%$ & Total & $\%$ \\
\hline Total & 104 & 100.0 & 182 & 100.0 & 286 & 100.0 \\
\hline Jefe & 54 & 51.9 & 13 & 7.1 & 67 & 23.4 \\
\hline Esposo/a & 11 & 10.6 & 51 & 28.0 & 62 & 21.7 \\
\hline $\mathrm{Hijo/a}$ & 38 & 36.5 & 80 & 44.0 & 118 & 41.3 \\
\hline Nieto/a & 0 & 0.0 & 16 & 8.8 & 16 & 5.6 \\
\hline Padre o madre & 0 & 0.0 & 4 & 2.2 & 4 & 1.4 \\
\hline Otro parentesco & 1 & 1.0 & 18 & 9.9 & 19 & 6.6 \\
\hline Total & 104 & 36.4 & 182 & 63.6 & 286 & 100.0 \\
\hline \multirow[b]{2}{*}{$\begin{array}{l}\text { Relación } \\
\text { de parentesco }\end{array}$} & \multicolumn{6}{|c|}{ Avecindado } \\
\hline & Participa & $\%$ & $\begin{array}{c}\text { No } \\
\text { participa }\end{array}$ & $\%$ & Total & $\%$ \\
\hline Total & 71 & 100.0 & 191 & 100.0 & 262 & 100.0 \\
\hline Jefe & 37 & 52.1 & 39 & 20.4 & 76 & 29.0 \\
\hline Esposo/a & 10 & 14.1 & 57 & 29.8 & 67 & 25.6 \\
\hline Hijo/a & 22 & 31.0 & 74 & 38.7 & 96 & 36.6 \\
\hline Nieto/a & 2 & 2.8 & 10 & 5.2 & 12 & 4.6 \\
\hline Padre o madre & 0 & 0.0 & 6 & 3.1 & 6 & 2.3 \\
\hline Otro parentesco & 0 & 0.0 & 5 & 2.6 & 5 & 1.9 \\
\hline \multirow[t]{2}{*}{ Total } & 71 & 27.1 & 191 & 72.9 & 262 & 100.0 \\
\hline & \multicolumn{6}{|c|}{ Posesionario } \\
\hline $\begin{array}{l}\text { Relación } \\
\text { de parentesco }\end{array}$ & Participa & $\%$ & $\begin{array}{c}\text { No } \\
\text { participa }\end{array}$ & $\%$ & Total & $\%$ \\
\hline Total & 28 & 100.0 & 21 & 100.0 & 49 & 100.0 \\
\hline Jefe & 11 & 39.3 & 3 & 14.3 & 14 & 28.6 \\
\hline Esposo/a & 0 & 0.0 & 11 & 52.4 & 11 & 22.4 \\
\hline Hijo/a & 16 & 57.1 & 6 & 28.6 & 22 & 44.9 \\
\hline Nieto/a & 0 & 0.0 & 0 & 0.0 & 0 & 0 \\
\hline Padre o madre & 0 & 0.0 & 0 & 0.0 & 0 & 0 \\
\hline Otro parentesco & 1 & 3.6 & 1 & 4.8 & 2 & 4.1 \\
\hline Total & 28 & 57.1 & 21 & 42.9 & 49 & 100.0 \\
\hline
\end{tabular}




\begin{tabular}{|c|c|c|c|c|c|c|}
\hline \multirow{2}{*}{$\begin{array}{l}\text { Relación } \\
\text { de parentesco }\end{array}$} & \multicolumn{6}{|c|}{ Total } \\
\hline & Participa & $\%$ & $\begin{array}{c}\text { No } \\
\text { participa }\end{array}$ & $\%$ & Total & $\%$ \\
\hline Total & 203 & 100.0 & 394 & 100.0 & 597 & 100.0 \\
\hline Jefe & 102 & 50.2 & 55 & 14.0 & 157 & 26.3 \\
\hline Esposo/a & 21 & 10.3 & 119 & 30.2 & 140 & 23.5 \\
\hline Hijo/a & 76 & 37.4 & 160 & 40.6 & 236 & 39.5 \\
\hline Nieto/a & 2 & 1.0 & 26 & 6.6 & 28 & 4.7 \\
\hline Padre o madre & 0 & 0 & 10 & 2.5 & 10 & 1.7 \\
\hline Otro parentesco & 2 & 1.0 & 24 & 6.1 & 26 & 4.4 \\
\hline Total & 203 & 34.0 & 394 & 66.0 & 597 & 100.0 \\
\hline
\end{tabular}

Fuente: Elaboración propia con base en los resultados de los cuestionarios a hogares.

parcelas (Cuadro 7), muestra que el hogar y la familia son las principales unidades de organización del trabajo. La mayor parte de las personas participan por cuenta propia (52\%) y como trabajador familiar sin pago (40.4\%). Destaca que tres avecindados (4.1\%) participan bajo la figura organizativa de socios, lo que significa que, a pesar de no tener la titularidad de los derechos sobre las parcelas, participan en tales actividades a través de las redes familiares (trabajadores familiares) o aportan trabajo o dinero junto con ejidatarios o posesionarios para el desarrollo de las actividades económicas en esos espacios.

\section{Solares}

En los solares existe una importante participación de miembros del hogar en las actividades: $85.9 \%$ de personas en hogares ejidatarios ( 256 de un total de 298 personas) participaron en algún tipo de actividad; $88.2 \%$ en los hogares avecindados (232 de un total de 263 personas), y $96 \%$ en los hogares posesionarios (48 de un total de 50 personas) (Cuadro 8).

En este ámbito territorial, la participación de hijos/as y esposos/as aumenta considerablemente, y no es menor la participación de los jefes de hogar (Cuadro 8). En los hogares avecindados y los posesionarios la participación de los jefes/as de hogar (29.7 y 29.2\%, respectivamente) es mayor que la de los jefes/as de los hogares ejidatarios (21.9\%). Mientras que la participación relativa del cónyuge del hogar avecindado (28\%) es mayor a 


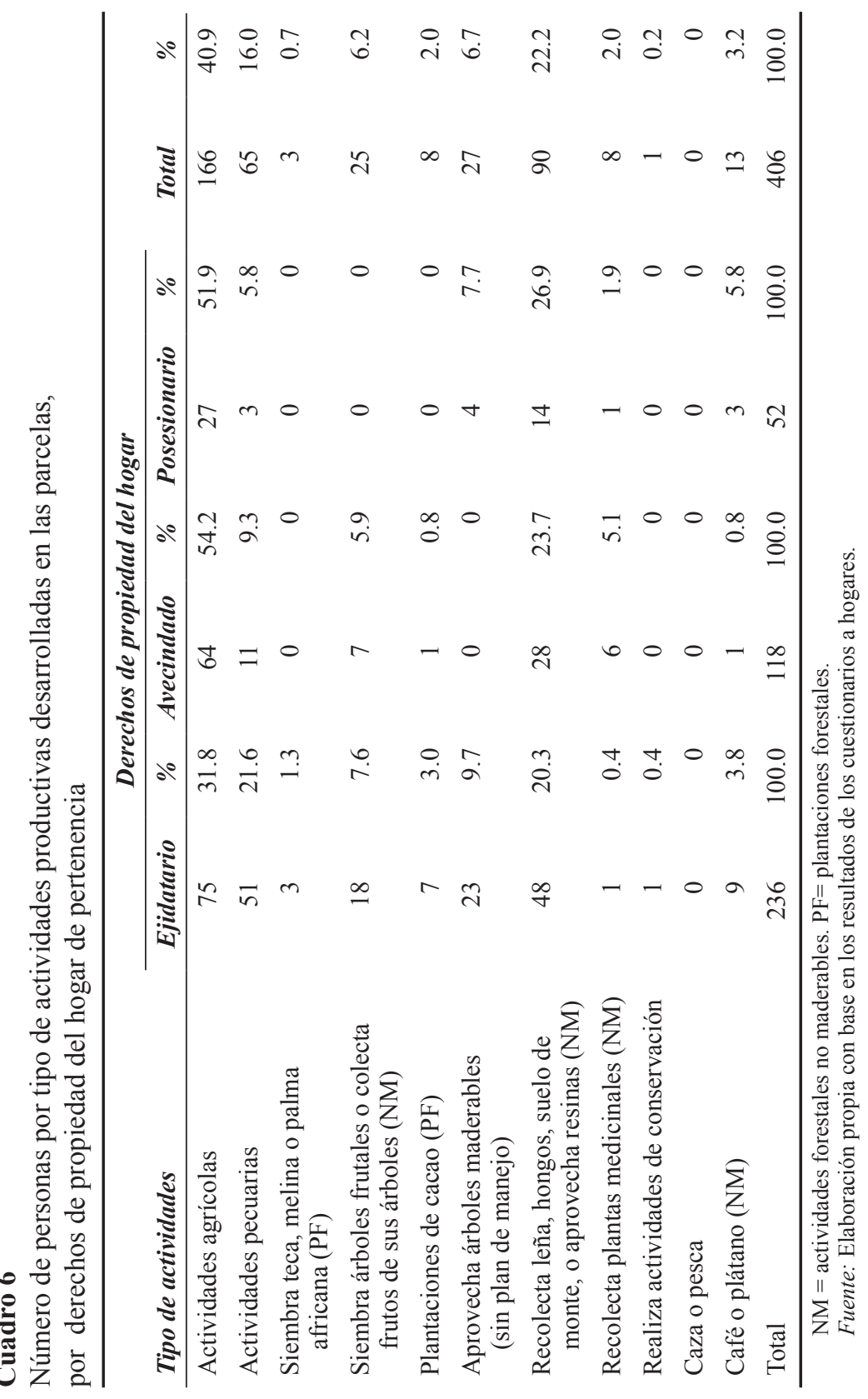




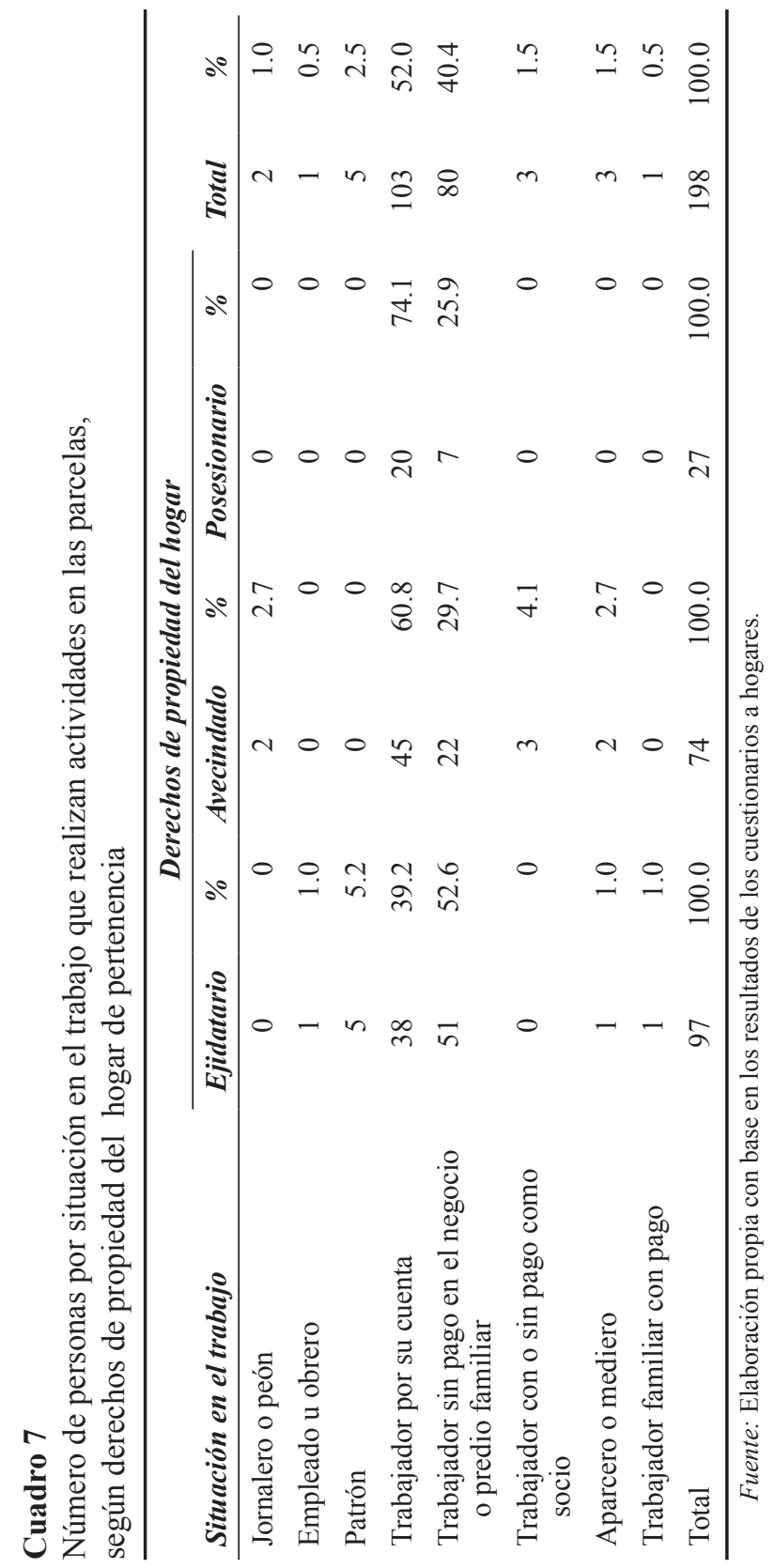


la de sus contrapartes en los hogares ejidatarios y en los posesionarios (23.4 y $22.9 \%$, respectivamente). Finalmente, los hijos/as de hogares avecindados tienen una participación relativa menor $(34.5 \%)$ a la registrada en los hogares ejidatarios y posesionarios (41.4 y $43.8 \%$, respectivamente).

Las actividades en que más participan los miembros del hogar son los quehaceres del hogar (407 personas), seguido de la cría de animales de traspatio (397 personas) y el deshierbe del solar (228) (Cuadro 9).

\section{Cuadro 8}

Número de personas que durante el año 2014 trabajaron en el solar, por relación de parentesco con el jefe del hogar según derechos de propiedad del hogar

\begin{tabular}{|c|c|c|c|c|c|c|}
\hline \multirow[b]{2}{*}{$\begin{array}{l}\text { Relación } \\
\text { de parentesco }\end{array}$} & \multicolumn{6}{|c|}{ Ejidatario } \\
\hline & Participa & $\%$ & $\begin{array}{c}\text { No } \\
\text { participa }\end{array}$ & $\%$ & Total & $\%$ \\
\hline Total & 256 & 100.0 & 42 & 100.0 & 298 & 100.0 \\
\hline Jefe & 56 & 21.9 & 12 & 28.6 & 68 & 22.8 \\
\hline Esposo/a & 60 & 23.4 & 5 & 11.9 & 65 & 21.8 \\
\hline Hijo/a & 106 & 41.4 & 14 & 33.3 & 120 & 40.3 \\
\hline Nieto/a & 12 & 4.7 & 9 & 21.4 & 21 & 7.0 \\
\hline Padre o madre & 3 & 1.2 & 1 & 2.4 & 4 & 1.3 \\
\hline Otro parentesco & 19 & 7.4 & 1 & 2.4 & 20 & 6.7 \\
\hline \multirow[t]{2}{*}{ Total } & 256 & 85.9 & 42 & 14.1 & 298 & 100.0 \\
\hline & \multicolumn{6}{|c|}{ Avecindado } \\
\hline $\begin{array}{l}\text { Relación } \\
\text { de parentesco }\end{array}$ & Participa & $\%$ & $\begin{array}{c}\text { No } \\
\text { participa }\end{array}$ & $\%$ & Total & $\%$ \\
\hline Total & 232 & 100.0 & 31 & 100.0 & 263 & 100.0 \\
\hline Jefe & 69 & 29.7 & 7 & 22.6 & 76 & 28.9 \\
\hline Esposo/a & 65 & 28.0 & 3 & 9.7 & 68 & 25.9 \\
\hline Hijo/a & 80 & 34.5 & 15 & 48.4 & 95 & 36.1 \\
\hline Nieto/a & 12 & 5.2 & 0 & 0.0 & 12 & 4.6 \\
\hline Padre o madre & 2 & 0.9 & 4 & 12.9 & 6 & 2.3 \\
\hline Otro parentesco & 4 & 1.7 & 2 & 6.5 & 6 & 2.3 \\
\hline Total & 232 & 88.2 & 31 & 11.8 & 263 & 100.0 \\
\hline
\end{tabular}




\section{Cuadro 8}

(concluye)

\begin{tabular}{|c|c|c|c|c|c|c|}
\hline \multirow[b]{2}{*}{$\begin{array}{l}\text { Relación } \\
\text { de parentesco }\end{array}$} & \multicolumn{6}{|c|}{ Posesionario } \\
\hline & Participa & $\%$ & $\begin{array}{c}\text { No } \\
\text { participa }\end{array}$ & $\%$ & Total & $\%$ \\
\hline Total & 48 & 100.0 & 2 & 100.0 & 50 & 100.0 \\
\hline Jefe & 14 & 29.2 & 0 & 0 & 14 & 28.0 \\
\hline Esposo/a & 11 & 22.9 & 0 & 0 & 11 & 22.0 \\
\hline $\mathrm{Hijo/a}$ & 21 & 43.8 & 2 & 100.0 & 23 & 46.0 \\
\hline Nieto/a & 0 & 0 & 0 & 0 & 0 & 0 \\
\hline Padre o madre & 0 & 0 & 0 & 0 & 0 & 0 \\
\hline Otro parentesco & 2 & 4.2 & 0 & 0 & 2 & 4.0 \\
\hline \multirow[t]{2}{*}{ Total } & 48 & 96.0 & 2 & 4.0 & 50 & 100.0 \\
\hline & \multicolumn{6}{|c|}{ Total } \\
\hline $\begin{array}{l}\text { Relación } \\
\text { de parentesco }\end{array}$ & Participa & $\%$ & $\begin{array}{c}\text { No } \\
\text { participa }\end{array}$ & $\%$ & Total & $\%$ \\
\hline Total & 536 & 100.0 & 75 & 100.0 & 611 & 100.0 \\
\hline Jefe & 139 & 25.9 & 19 & 25.3 & 158 & 25.9 \\
\hline Esposo/a & 136 & 25.4 & 8 & 10.7 & 144 & 23.6 \\
\hline Hijo/a & 207 & 38.6 & 31 & 41.3 & 238 & 39.0 \\
\hline Nieto/a & 24 & 4.5 & 9 & 12.0 & 33 & 5.4 \\
\hline Padre o madre & 5 & 0.9 & 5 & 6.7 & 10 & 1.6 \\
\hline Otro parentesco & 25 & 4.7 & 3 & 4.0 & 28 & 4.6 \\
\hline Total & 536 & 87.7 & 75 & 12.3 & 611 & 100.0 \\
\hline
\end{tabular}

Fuente: Elaboración propia con base en los resultados de los cuestionarios a hogares.

En los hogares ejidatarios, la principal actividad realizada fueron los quehaceres del hogar (Cuadro 9), a la cual se incorporaron 183 personas. La segunda actividad más desarrollada fue la cría de animales de traspatio (gallinas, gallos, pollos, guajolotes y patos), a la cual se incorporaron 148 personas. Deshierbar el solar fue la tercera actividad (con la participación de 102 personas). Los huertos familiares fueron sembrados o cuidados por 39 personas; la cría de cerdo, borrego o chivo fue desarrollada por 28 personas, y nueve personas atendieron un negocio.

La participación de los miembros de los hogares avecindados sigue una distribución muy similar a la de los ejidatarios (Cuadro 9). La principal di- 


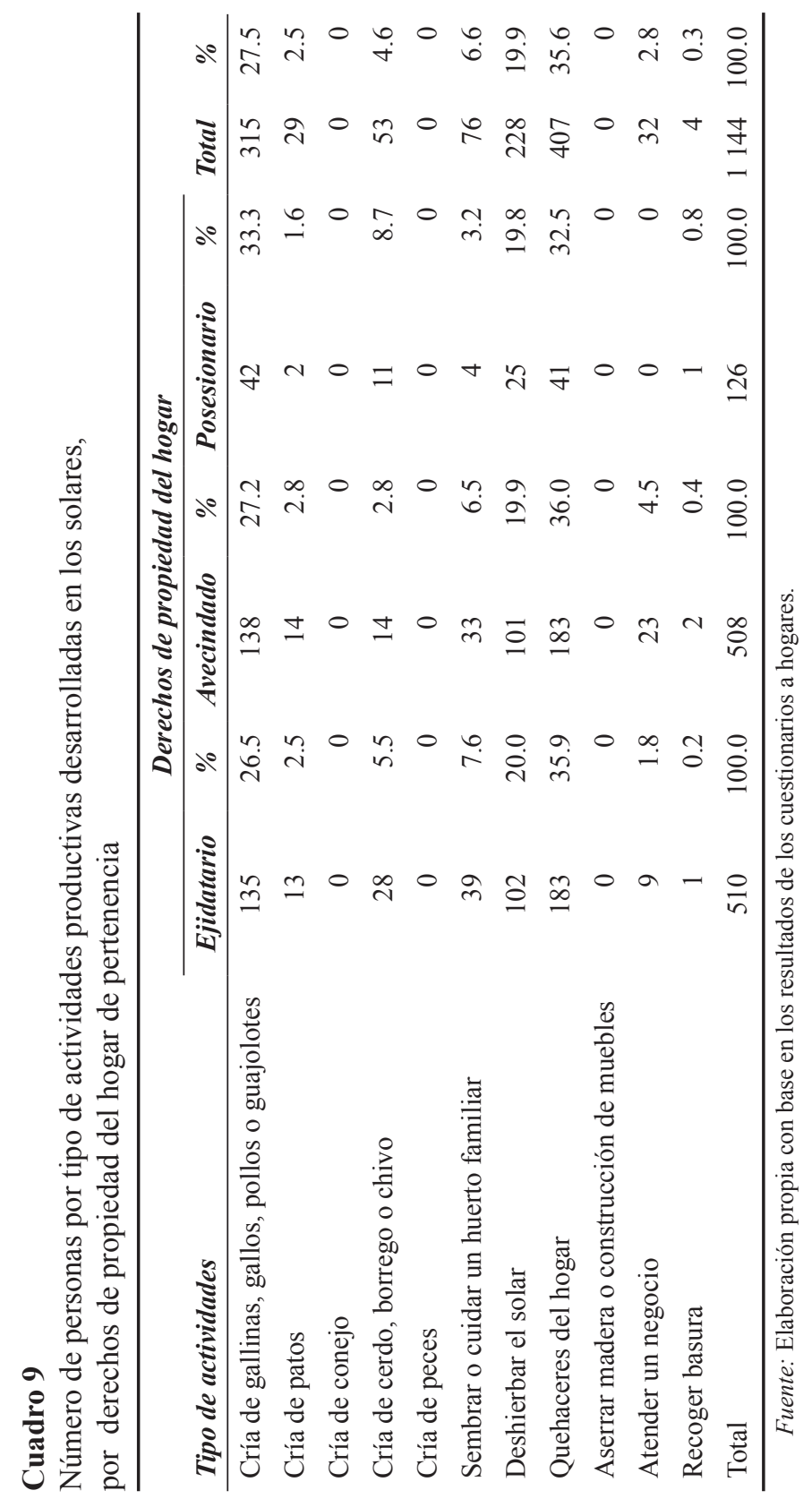


ferencia es que en los hogares avecindados hay mayor participación de personas (23) en un negocio y existe una menor participación de individuos (14) en la cría de cerdo, borrego o chivo.

En los hogares posesionarios los quehaceres del hogar y la cría de animales de traspatio son las actividades más desarrolladas (41 y 44 personas, respectivamente). Deshierbar el solar fue la tercera actividad a la cual se incorporó el mayor número de individuos (25). Finalmente, 11 sujetos criaron cerdo, borrego o chivo, y no hubo nadie dedicado a atender un negocio.

Prácticamente todos los miembros de los hogares de ejidatarios, posesionarios y avecindados declararon desarrollar las actividades del solar como trabajadores familiares sin pago (92.5\%) (Cuadro 10). Destaca que dos miembros de los hogares ejidatarios afirmaron contratar personas para desarrollar alguna actividad en el solar. Cinco avecindados manifestaron ser ayudantes en el negocio familiar y dos personas más participan en las actividades del solar como empleados u obreros. En este ámbito, el hogar es la base de la organización del trabajo.

\section{Discusión y conclusiones}

Este artículo analizó la organización del trabajo y sus formas de expresión territorial en los ejidos de la frontera entre Tabasco y Chiapas para explorar la transferencia del capital social desde los hogares al orden de lo colectivo, y su expresión territorial en solares, parcelas y tierras de uso común; lo que en este trabajo hemos llamado territorialización del capital social.

La aplicación de cuestionarios a los hogares permitió captar algunos datos reveladores que nos permiten interpretar y problematizar la relación entre el capital social, el territorio y la apropiación forestal comunitaria, lo cual se desarrolla a continuación.

La propiedad de la tierra y la familia son dispositivos institucionales que ofrecen oportunidades diferenciales para las acciones cooperativas entre los individuos, según los derechos de propiedad del hogar sobre las tierras (ejidatarios, posesionarios y avecindados), el ámbito territorial en el que se suceden (parcelas, solares y tierras de uso común) y el capital social del hogar (expresado a través de las relaciones de parentesco y la situación laboral).

En cuanto a los ámbitos territoriales y los derechos de propiedad, la información recabada indica que en las tierras de uso común el aprovechamiento forestal no es practicado comunitariamente, y que esas actividades son desarrolladas por pocos miembros de los hogares ejidatarios analizados y por muy pocos integrantes de los hogares posesionarios y avecindados. 


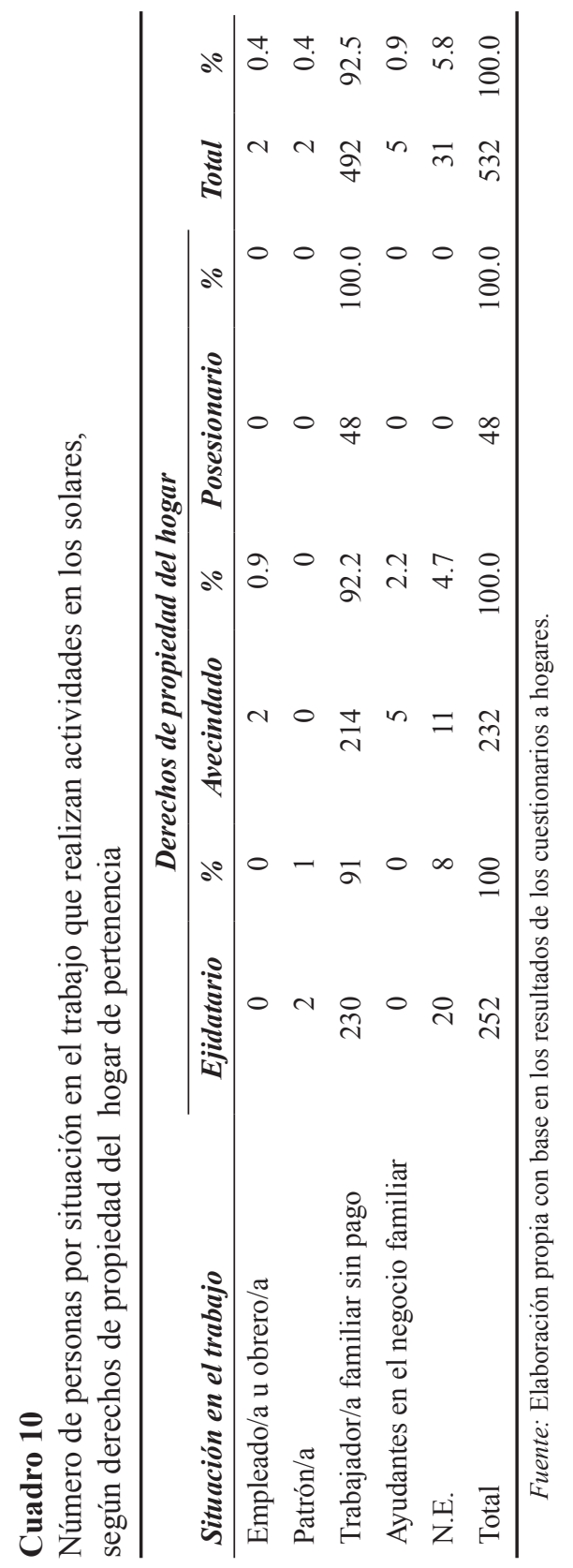


En cuanto al capital social para la apropiación forestal comunitaria, los datos muestran que éste se moviliza a través del hogar y la familia, y se sostiene mediante el trabajo no remunerado entre el jefe del hogar, cónyuge e hijos (trabajador por cuenta propia y trabajador familiar sin pago); mientras que su intensidad e importancia relativa aumentan en los ámbitos territoriales donde la ley agraria ha privilegiado la apropiación individual de los recursos (parcelas y solares). En estos ámbitos territoriales la participación de los miembros del hogar se incrementa considerablemente. En los solares las relaciones de parentesco de quienes participan en las actividades productivas son más diversas que en las parcelas, ya que en los solares se aprecia la incorporación de padres, nietos y de quienes tienen otras relaciones de parentesco con el jefe del hogar. En los hogares posesionarios destaca que el esposo/a únicamente es incorporado en actividades domésticas y de traspatio en los solares, prescindiendo de su movilización en las parcelas. Adicionalmente, la movilización del capital social permite a los avecindados-quienes jurídicamente no tienen derechos reconocidos sobre las tierras de uso común y las parcelas- acceder a los beneficios del trabajo que se desarrolla en esos ámbitos territoriales, incorporándose como trabajadores familiares sin pago u organizados como socios o aparcería.

Esta forma de organización del trabajo y los lazos de parentesco inscritos en ella, reflejan un incipiente proceso de construcción del capital social requerido para la acción colectiva, y específicamente podrían estar mostrando una estructura comunitaria fragmentada y concentrada en grupos de hogares que, a través de las relaciones de parentesco, dan acceso al aprovechamiento de recursos en tierras de uso común y parcelas a quienes no tienen derecho de propiedad sobre la tierra (avecindados).

Esta estructura de participación se ajusta considerablemente bien a lo descrito por Granovetter (1973, p. 1378), quien señala que el capital social está conformado por vínculos débiles y fuertes. Para este autor, los vínculos débiles son importantes para la integración de los individuos en el orden de lo comunitario, mientras que la prevalencia de vínculos fuertes -aquellos que tienden a alimentar la cohesión social- resulta en una fragmentación de la participación en diversos subgrupos. Sobre ello, Ostrom y Ahn (2003, p. 190) señalan que las relaciones familiares y de parentesco conforman una red de relaciones demasiado fuertes, de modo que las normas de reciprocidad surgidas en las redes familiares y de parentesco generalmente no se expanden a la sociedad como un todo, "y por tal razón, los lazos débiles son más importantes que los lazos personales e intensos en lo que se refiere al sostenimiento de la estabilidad social y la acción colectiva”. En una revisión de la evidencia empírica asociada a esta hipótesis, Granovetter (1983, p. 208) 
encuentra que los lazos débiles son de gran importancia para establecer puentes entre distintos grupos, más allá de los círculos de pertenencia; no obstante, Granovetter $(1973,1983)$ también señala que, cuando los lazos comunitarios se han roto, la acción colectiva es transferida a grupos primarios.

La transferencia de la acción colectiva a grupos primarios es reportada por Leigh (2007) en dos unidades agrarias de Durango, donde registró la presencia de subgrupos de trabajo (o socios) que funcionan en respuesta a la ineficiencia y corrupción de la silvicultura organizada en el ámbito comunitario. Por su parte, analizando los retos que enfrentan los ejidos para consolidar empresas forestales comunitarias, Wilshusen (2007, p. 202) también reporta la presencia de subgrupos de trabajo (o socios) que han surgido en dos ejidos forestales de Quintana Roo, como estrategia para "superar ineficiencias crónicas y conflictos" con la administración de los recursos económicos a nivel comunitario. Cabe destacar que en una de las unidades agrarias analizadas por Wilshusen (2007, p. 205), las subsecuentes divisiones de los grupos de trabajo estuvieron representadas por clanes familiares e incluso "familias individuales" (refiriéndose a hogares). De esa forma, la organización en estos subgrupos permitió la transferencia de poderes del orden de lo comunitario a los líderes de los grupos de trabajo, suplantando así las funciones del comisariado ejidal y de la asamblea (Wilshusen, 2007, p. 221). Para dichos autores, la individualización de la apropiación de los recursos naturales a través de los grupos de trabajo es una respuesta adaptativa al "fracaso" de la organización comunitaria para la apropiación colectiva de los recursos en las tierras de uso común. En este sentido, en nuestros casos de estudio la transferencia de la acción colectiva a los grupos primarios podría relacionarse con quebrantos a nivel comunitario, hipótesis que tendría que ser comprobada en futuros trabajos.

Siguiendo la línea reflexiva de Wilshusen (2007), Leigh (2007) y Granovetter $(1973 ; 1983)$, el escaso uso de tierras de uso común, el aprovechamiento de recursos forestales maderables y no maderables fuertemente sustentado en las unidades domésticas y las familias, y la presencia de subgrupos de trabajo (socios), indican una débil organización comunitaria del aprovechamiento forestal en los ejidos analizados. En contraparte, la fuerte capacidad de movilización de capital social para desarrollar actividades principalmente en los solares, en segundo término en las parcelas, y en tercer término en las tierras de uso común, indica una fragmentada organización colectiva del trabajo, donde los hogares y las familias imponen las condiciones de intercambio entre los individuos; y si bien llegan a trascender el marco de las unidades domésticas, mediante la figura organizativa de los socios (o subgrupos de trabajo), existe una incipiente territorialización del 
capital social en tierras de uso común para la apropiación comunitaria de los recursos forestales maderables y no maderables.

Datos asociados a un estudio realizado por Saavedra, López y Castellanos (2015) en cuatro de las cinco comunidades analizadas en este trabajo (Pochitocal, Profesor Arcadio Zentella, Loma Triste y Miraflores), cuyo objetivo fue caracterizar los sistemas agroecológicos, apuntan algunos elementos sobre la escasa apropiación comunitaria de las tierras de uso común. ${ }^{12}$ En el ejido Miraflores se señaló que las tierras de uso común no son tocadas y no se explotan. En el ejido Profesor Arcadio Zentella las tierras de uso común están protegidas bajo el esquema de Parque Nacional. El ejido Pochitocal aparentemente ya no cuenta con tierras de uso común. Finalmente, en el ejido Loma Triste las tierras de uso común están bajo protección (no se indica en qué modalidad) y son aprovechadas. No obstante, no existe más información que nos permita ahondar en las razones que explican la escasa apropiación comunitaria de los recursos en las tierras de uso común en estos ejidos. Para ello, haría falta llevar a cabo una segunda etapa de trabajo de campo para rescatar elementos clave, como son las trayectorias históricas seguidas por los ejidos, el proceso de parcelamiento derivado de su posible incorporación al Programa de Certificación de Derechos Ejidales y Titulación de Solares Urbanos (Procede), las reglas y restricciones de apropiación de recursos en las tierras de uso común, si existe una baja confianza a nivel comunitario, o si hay lazos de confianza más fuertes dentro de los límites de las relaciones de parentesco ${ }^{13}$ y del hogar. ${ }^{14}$

En los cinco ejidos analizados, la incipiente construcción del capital social de la apropiación forestal comunitaria está acompañada de una importante restricción de la acción colectiva en las tierras de uso común, espacio en el que los ejidatarios tienen una posición de intermediación (como propietarios de la tierra) y, en tal sentido, pueden restringir la posibilidad de aumentar los intercambios colaborativos entre actores (véase Marsden, 1983, pp. 712-713), provocando que los sistemas de acción individual y colectiva

12 Los datos que aquí se muestran aún no han sido publicados. Se agradece a los autores la facilidad otorgada para poder rescatar esta información de sus bases de datos.

13 Esta hipótesis deriva de lo encontrado por Fukuyama (1995) y por Ostrom y Ahn (2003, p. 188) en un amplio estudio realizado sobre la confianza.

14 Esta hipótesis se sustenta en Olson (1992, p. 209), quien señala que los incentivos sociales para la cooperación pueden ser usados con mayor éxito mientras más reducido sea el número de interactuantes, porque de acuerdo con Cante (2007, p. 168), es más fácil que surjan relaciones de confianza y reciprocidad, ya que las relaciones de transacción y organización son menos costosas y es más fácil conocer el grado de compromiso de los individuos para cooperar en la acción colectiva. 
estén diferenciados territorialmente. En tal sentido, la noción de territorialización del capital social, que se propone en este estudio, ha permitido problematizar los retos que impone la organización territorial del trabajo a la apropiación comunitaria de los recursos forestales. No obstante, queda por delante conocer los problemas comunitarios que explican la escasa territorialización del capital social en las tierras de uso común de estos ejidos. En todo caso, la formación de capital social a nivel comunitario es relevante porque existe significativa evidencia empírica que indica que su ausencia favorece la sobreexplotación y destrucción de los recursos de uso común, asociada a regímenes de libre acceso y presencia de conflictos (Ostrom, 2000, 2015, p. 294; Merino, 2004).

\section{Bibliografía}

Álvarez, P. (2006). Los recursos de uso común en México: un acercamiento conceptual. Gaceta Ecológica, 80, 5-17. Recuperado de http://www. redalyc.org/articulo.oa? $\mathrm{id}=53908001$

Baca, N. (2002). Experiencias y significados del contexto del hogar en la relación trabajo doméstico-extradoméstico. Papeles de Población, 8(32), 199-243. Recuperado de http://www.redalyc.org/articulo.oa?id=11203208

Barton, D., Merino, L. y Barry, D. (2007). El manejo comunitario en sentido estricto: las empresas forestales comunitarias de México. En D. Bray, L. Merino y D. Barry (eds.), Los bosques comunitarios de México. Manejo sustentable de paisajes forestales (pp. 21-49). Ciudad de México: Instituto Nacional de Ecología / Secretaría de Medio Ambiente, Recursos Naturales y Pesca.

Boege, E. (2008). El patrimonio biocultural de los pueblos indígenas de México. Hacia la conservación in situ de la biodiversidad y agrodiversidad en los territorios indígenas. Ciudad de México: Instituto Nacional de Antropología e Historia / Comisión Nacional para el Desarrollo de los Pueblos Indígenas.

Burt, R. (1982). Towards a structural theory of action. Network models of social structure, perception and action. Estados Unidos: Academic Press.

Burt, R. (1997). The contingent value of social capital. Administrative Science Quarterly, 42(2), 339-365. Recuperado de https://www.jstor.org/ stable/pdf/2393923.pdf?refreqid=search\%3Af98be97bc9cc855f3f09cd 1ebbaf2061

Camarena, R. (2003). Repensando a la familia: algunas aportaciones de la perspectiva de género. Estudios Demográficos y Urbanos, 18(2), 255-

Estudios Demográficos y Urbanos, vol. 35, núm. 1 (103), enero-abril, 2020, pp. 9-50 
297. Recuperado de http://estudiosdemograficosyurbanos.colmex.mx/ index.php/edu/article/view/1163/1156

Cante, F. (2007). Acción colectiva, metapreferencias y emociones. Cuadernos de Economía, 26(47), 151-174. Recuperado de http://www.fce.unal. edu.co/media/files/cuadernos/47/v26n47_cante_2007.pdf

Chapela, F. (2007). El manejo forestal comunitario indígena en la Sierra de Juárez, Oaxaca. En D. Bray, L. Merino y D. Barry (eds.), Los bosques comunitarios de México. Manejo sustentable de paisajes forestales (pp. 123-146). Ciudad de México: Instituto Nacional de Ecología / Secretaría de Medio Ambiente, Recursos Naturales y Pesca.

Cortés, F. (1990). La importancia analítica del ámbito doméstico. En G. de la Peña, J. M. Durán, A. Escobar y J. García de Alba (comps.), Crisis, conflicto y sobrevivencia: estudios sobre la sociedad urbana en México (pp. 415-438). Guadalajara: Universidad de Guadalajara.

De Oliveira, O. y Ariza, M. (1999). Trabajo, familia y condición femenina: una revisión de las principales perspectivas de análisis. Papeles de Población, 5(20), 89-127. Recuperado de http://www.redalyc.org/articulo. oa?id=11202005

Durán-Medina, E., Mas, J. F. y Velázquez, A. (2007). Cambios en las coberturas de vegetación y usos del suelo en regiones con manejo forestal comunitario y áreas naturales protegidas de México. En D. Bray, L. Merino y D. Barry (eds.), Los bosques comunitarios de México. Manejo sustentable de paisajes forestales (pp. 267-299). Ciudad de México: Instituto Nacional de Ecología / Secretaría de Medio Ambiente, Recursos Naturales y Pesca.

Fernández-Huerga, E. (2010). La teoría de la segmentación del mercado de trabajo: enfoques, situación actual y perspectivas de futuro. Investigación Económica, 69(273), 115-150. Recuperado de http://www.redalyc.org/ articulo.oa? $\mathrm{id}=60114744004$

Flap, H. D. (1991). Social capital in the reproduction of inequality. Comparative Sociology of Family, Health and Education, 20, 6179-6202.

Granovetter, M. (1973). The strength of weak ties. American Journal of Sociology, 78(6), 1360-1380. Recuperado de https://www.jstor.org/ stable/pdf/2776392.pdf?refreqid=search\%3A94c9effdb6aab10911 fdc8 329502ef83

Granovetter, M. (1983). The strength of weak ties: A network theory revisited. Sociological Theory, 1, 201-233. Recuperado de https://www.jstor. org/stable/pdf/202051.pdf?refreqid=search\%3A94c9effdb6aab10911fd c8329502ef83 
Haesbaert, R. (2011). El mito de la desterritorialización. Del "fin de los territorios" a la multiterritorialidad. Ciudad de México: Siglo XXI.

Hardin, J. (1968). The tragedy of commons. Science, 162(3859), 1243-1248. Recuperado de https://www.jstor.org/stable/pdf/1724745.pdf?refreqid= excelsior\%3Aa8da907ee6d676a92668b33555f1dfc4

Hinojosa, J. (1981). Formas de tenencia de la tierra en México. Jurídica. Anuario del Departamento de Derecho de la Universidad Iberoamericana, 13(1), 613-623. Recuperado de https://revistas-colaboracion.juri dicas.unam.mx/index.php/juridica/article/view/10905/9977

INEGI. (2010). Marco conceptual del Censo de Población y Vivienda 2010. Aguascalientes, México: Instituto Nacional de Estadística y Geografía. Recuperado de http://www.beta.inegi.org.mx/app/biblioteca/ficha.html? upc $=702825002392$

Leigh, P. (2007). Nuevas estrategias organizativas en el manejo comunitario de bosques en Durango, México. En D. Bray, L. Merino y D. Barry (eds.), Los bosques comunitarios de México. Manejo sustentable de paisajes forestales (pp.163-194). Ciudad de México: Instituto Nacional de Ecología.

Ley de Desarrollo Forestal Sustentable. (2003). Ley de Desarrollo Forestal Sustentable. Diario Oficial de la Federación, 25 de febrero. Recuperado de http://www.dof.gob.mx/nota_detalle.php?codigo $=705172 \& \mathrm{fec}$ ha $=25 / 02 / 2003$

Lin, N. (1982). Social resources and instrumental action. En P. V. Marsden y N. Lin (eds.), Social structure and network analysis (pp. 131-145). Estados Unidos: Sage.

Lira, L. F. (1975). Introducción al estudio de la familia y los hogares en América Latina (Documento de Trabajo, núm. 10, serie OI-Celade). Santiago de Chile: Centro Latinoamericano de Demografía. Recuperado de http://repositorio.cepal.org/handle/11362/7939

Marsden, P. (1983). Restricted access in networks and models of power. The American Journal of Sociology, 88(4), 686-717. Recuperado de https:// www.jstor.org/stable/pdf/2779481.pdf?refreqid=excelsior\%3Aa8f0afa $1276 \mathrm{~d} 4 \mathrm{~b} 846 \mathrm{~b} 2704 \mathrm{e} 3 \mathrm{c} 6 \mathrm{eecbfb}$

McKean, M. (2000). Common property: What is it, what is it good for, and what makes it work? En C. Gibson, M. A. McKean y E. Ostrom (eds.), People and forests: Communities, institutions, and governance (pp. 2755). Cambridge, MA: MIT Press.

Merino, L. (2004). Conservación o deterioro. El impacto de las políticas públicas en las instituciones comunitarias y en los usos de los bosques. Ciudad de México: Secretaría de Medio Ambiente y Recursos Naturales 
/ Instituto Nacional de Ecología / Consejo Civil Mexicano para la Agricultura Sostenible, A.C.

Merino, L. y Martínez, A. (2014). A vuelo de pájaro: las condiciones de las comunidades con bosque templados en México. Ciudad de México: Comisión Nacional para el Uso de la Biodiversidad, Conabio.

Olson, M. (1992). La lógica de la acción colectiva. En A. Batlle i Rubio (coord.), Diez textos básicos de ciencia política (pp. 203-220). Barcelona: Ariel.

Ostrom, E. (2000). El gobierno de los bienes comunes. La evolución de las instituciones de acción colectiva. Ciudad de México: Fondo de Cultura Económica / Universidad Nacional Autónoma de México, Centro Regional de Investigaciones Multidisciplinarias.

Ostrom, E. (2002). Reformulating the commons. Ambiente \& Sociedade, 10, 5-25. Recuperado de https://dx.doi.org/10.1590/S1414-753X200200 0100002

Ostrom, E. (2015). Comprender la diversidad institucional. Ciudad de México: Fondo de Cultura Económica / Universidad Nacional Autónoma de México.

Ostrom, E. y Ahn, T. K. (2003). Una perspectiva del capital social desde las ciencias sociales: capital social y acción colectiva. Revista Mexicana de Sociología, 65(1), 155-233. Recuperado de http://www.scielo.org.mx/ $\mathrm{pdf} / \mathrm{rms} / \mathrm{v} 65 \mathrm{n} 1 / \mathrm{v} 65 \mathrm{n} 1 \mathrm{a} 5 . \mathrm{pdf}$

Patiño, L. I. (2002). Población y manejo de comunitario de recursos naturales: el caso del municipio de Nuevo Zoquiapam. Estudios Agrarios, 21, 59-98. Recuperado de http://www.pa.gob.mx/publica/rev_21/LIBRO $\% 202-21 . p d f$

Pérez, M. (2004). Las tierras de uso común en ejidos certificados. Estudios Agrarios, 25, 235-246. Recuperado de http://www.pa.gob.mx/publica/ rev_25/Marco\%20Antonio\%20Pérez.pdf

Pizarro, N. (1998). Tratado de metodología de las ciencias sociales. Madrid: Siglo XXI.

Portales, L. (2013). El estudio del capital social de los hogares por medio de redes personales. Revista Hispana para el Análisis de Redes Sociales, 24(2), 80-108. Recuperado de https://revistes.uab.cat/redes/article/view/ v24-n2-portales/pdf-es

Portes, A. (2009). Las instituciones en el desarrollo latinoamericano. Ciudad de México: Siglo XXI.

Putnam, R. (1994). Social capital and public affairs. Bulletin of the American Academy of Arts and Sciences, 47(8), 5-19. Recuperado de https://www. 
jstor.org/stable/pdf/3824796.pdf?refreqid=excelsior\%3A88a1f8e87bdd $59 \mathrm{e} 27570 \mathrm{aeb} 7975159 \mathrm{c} 7$

Rau, V. (2006). La sociología de los mercados laborales en los estudios sobre el empleo agrícola. Gaceta Laboral, 12(3), 357-385. Recuperado de http: //www.redalyc.org/articulo.oa?id=33612304

Robles, H. (2005). Los tratos agrarios. La vía campesina de acceso a la tierra. La experiencia de San Ildefonso Tultepec. México: Centro de Estudios para el Desarrollo Rural Sustentable y la Soberanía Sustentable / Secretaría de la Reforma Agraria / Cámara de Diputados, LIX Legislatura.

Ruiz, J. I. (2003). Metodología de la investigación cualitativa. Bilbao: Universidad de Deusto.

Saavedra, A., López, D. y Castellanos, L. (2015). Cobertura vegetal y uso del suelo, zonificación y ordenación ambiental de la región fronteriza de Tabasco y Chiapas (Documento de Investigación). Ciudad de México: CentroGeo / Gobierno de Tabasco. Recuperado de https://centrogeo. repositorioinstitucional.mx/jspui/handle/1012/30

Schlanger, E. y Ostrom, E. (1992). Property-rights regimes and natural resources: A conceptual analysis. Land Economics, 68(3), 249-262. Recuperado de https://www.jstor.org/stable/pdf/3146375.pdf?refreqid=ex celsior\%3A289ba1103187e1933c18301b7f8ad6ec

Schneider, S. y Peyré, I. G. (2006). Territorio y enfoque territorial: de las referencias cognitivas a los aportes aplicados al análisis de los procesos sociales rurales. En M. Manzanal, G. Neiman y M. Lattuada (comps.), Desarrollo rural: organizaciones, instituciones y territorios (pp. 71-101). Buenos Aires: Centro Integral Comunicación, Cultura y Sociedad.

Smith, H. (2000). Semicommon property rights and scattering in the open fields. The Journal of Legal Studies, 29(1), 131-169. Recuperado de https:// www.jstor.org/stable/pdf/10.1086/468066.pdf?refreqid=excelsior\%3A65 e61d7e9ecb524eb3028cded3552fee

Tapinos, G. (1994). Crecimiento demográfico y crecimiento económico. En B. Zenteno y E. Ramírez (eds.), Políticas de población en Centroamérica, el Caribe y México (pp. 65-72). Ciudad de México: Instituto Nacional de Administración Pública de Guatemala / Instituto de Investigaciones Sociales de la Universidad Autónoma de México / Programa Latinoamericano de Actividades en Población.

Tarrés, M. L. (1992). Perspectivas analíticas en la sociología de la acción colectiva. Estudios Sociológicos, 10(30), 735-757. Recuperado de http:// estudiossociologicos.colmex.mx/index.php/es/article/view/946/946

Torrado, S. (1981). Sobre los conceptos de estrategias familiares de vida y 
procesos de reproducción de la fuerza de trabajo: notas teórico-metodológicas. Demografía y Economía, 15(2), 204-233. Recuperado de http:// estudiosdemograficosyurbanos.colmex.mx/index.php/edu/article/ view/512/505

Torrado, S. (2003). Historia de la familia en la Argentina moderna (18702000). Buenos Aires: Ediciones de la Flor

Torres, L., Ortega, S., Garrido, A. y Reyes, A. (2008). Dinámica familiar en familias con hijos e hijas. Revista Intercontinental de Psicología y Educación, 10(2), 31-56. Recuperado de http://www.redalyc.org/articulo. oa? $\mathrm{id}=80212387003$

Tuirán, R. (1996). Introducción. En M. López Barajas (comp.), Hogares, familias: desigualdad, conflicto, redes solidarias y parentales (pp. 1-5). Ciudad de México: Sociedad Mexicana de Demografía.

Vergara, R. (2010). Introducción. En R. Vergara (comp.), Organización e instituciones (pp. 17-47). Ciudad de México: Siglo XXI.

Warman, A. (2001). El campo mexicano en el siglo XX. Ciudad de México: Fondo de Cultura Económica.

Wilshusen, P. (2007). ¿Adaptación o fracaso colectivo? El surgimiento de "grupos de trabajo" en dos ejidos forestales de Quintana Roo, México. En D. Bray, L. Merino y D. Barry (eds.), Los bosques comunitarios de México. Manejo sustentable de paisajes forestales (pp. 195-230). Ciudad de México: Instituto Nacional de Ecología.

Wróblewski, J. (1988). La propiedad: tipología, axiología y política en el marco socialista. Crítica Jurídica. Revista Latinoamericana de Política, Filosofía y Derecho, 8, 49-58. Recuperado de http://historico.juridicas. unam.mx/publica/librev/rev/critica/cont/8/teo/teo4.pdf

\section{Acerca de los autores}

Mauricio Pablo Cervantes Salas es licenciado en Biología por la Facultad de Ciencias de la Universidad Nacional Autónoma de México; maestro en Demografía y doctor en Estudios de Población por El Colegio de México A.C. Actualmente es profesor investigador del Centro de Investigación en Ciencias de Información Geoespacial, A.C. (CentroGeo), institución en la que ha impartido el seminario "Manejo comunitario de recursos naturales" para la maestría en Geomática, y el curso "Espacio y desigualdad" para la maestría en Planeación Espacial. Sus temas de interés en la investigación están relacionados con desigualdad, familia, territorio y manejo comunitario de recursos naturales. ORCID: https://orcid.org/0000-0002-0173-2735 
Entre sus publicaciones se encuentran:

Cervantes S. M. (2018). Habituación e institucionalización del aprovechamiento y la conservación forestal comunitaria. Estudios Demográficos y Urbanos, 33(1), 9-42.

Montejano, J. A., Caudillo, C. y Cervantes, M. (2018). Vivienda de interés social y segregación espacial: un análisis de 124 conjuntos urbanos en el arco nororiente del Valle de México. Estudios Demográficos y Urbanos, 33(1), 187-224.

Adriana Aguilar Rodríguez es doctora en Sociología por la Universidad de Manchester, Reino Unido, maestra en Globalización y Desarrollo por la Universidad de Warwick, Reino Unido, y licenciada en Derecho por la Universidad Nacional Autónoma de México. Actualmente ocupa una Cátedra Conacyt en el Centro de Investigación en Ciencias de Información Geoespacial A.C. (CentroGeo). Su agenda de investigación consiste en el análisis cuantitativo y cualitativo de sistemas de gobernanza ambiental. Busca comprender cómo los actores, a través de sus redes sociales, coordinan sus acciones, cooperan, e intercambian recursos valiosos (capital humano, social, financiero). Así mismo, analiza qué tipos de mecanismos sociales formales e informales (confianza, reputación, reciprocidad, sanciones sociales) emergen en una red social para salvaguardar los objetivos individuales y/o públicos en contextos donde no existe un regulador central o el marco jurídico es difuso. ORCID: https://orcid.org/0000-0002-6590-3222

Entre sus publicaciones se encuentran:

Aguilar, A. y Gouritin, A. (2016). La adopción de la Declaración Americana sobre los Derechos de los Pueblos Indígenas: un análisis crítico desde el punto de vista de los derechos ambientales. Anuario Mexicano de Derecho Internacional, volumen XVII.

Daniel María López López es agrólogo, especialista en interpretación de imágenes satelitales del Centro Interamericano de Fotointerpretación de Bogotá, Colombia. Tiene una maestría en Ciencia, por el International Institute for Aerospace Survey and Earth Sciences en Holanda. Es maestro en Geomática por el Centro de Investigación en Ciencias de Información Geoespacial, A.C. (CentroGeo), en el cual se desempeña como técnico titular. La investigación que ha desarrollado se enfoca en la aplicación de modelos digitales del terreno para el análisis y el modelaje de problemas socioambientales, el análisis y la evaluación de la vulnerabilidad al cambio ambiental global, y el análisis de patrones espacio-temporales de vulnerabilidad del paisaje socioecológico al cambio ambiental global. Ha impartido el curso 
"Percepción remota aplicada a la agricultura", para la carrera Ingeniería Agrícola, en la Universidad Nacional Autónoma de México; así como el "Curso introductorio a los sistemas de información geográfica y percepción remota", para la maestría en Zonas Áridas, del Centro de Investigaciones Biológicas del Noroeste, La Paz. ORCID: https://orcid.org/0000-0003-2816$590 \mathrm{X}$

Entre sus publicaciones se encuentran:

López López, D. (2014). El paisaje socioecológico, modelado geoespacial y análisis de vulnerabilidad ante el cambio climático global. En L. Medina, C. Tejeda, A. Carrillo y T. M. Rioja (eds.), Gestión territorial y manejo de recursos naturales: fauna silvestre y sistemas agropecuarios. México: Universidad Autónoma de Chiapas.

Aristides Saavedra Guerrero es agrólogo y especialista en Levantamiento de Suelos por el Centro Interamericano de Fotointerpretación, de Bogotá, Colombia. Tiene un diplomado en Geomática por el Centro de Investigación en Ciencias de Información Geoespacial, A.C. (CentroGeo) y ha tomado cursos sobre evaluación de tierras con metodología FAO, mineralogía y micromorfología del suelo, geomorfología, y evaluación del efecto ambiental. Actualmente se desempeña como técnico titular en el CentroGeo. Sus temas de investigación son: planeación territorial y cambio climático, aplicación de modelos digitales del terreno en el análisis fisiográfico y geomorfológico, análisis, clasificación y evaluación de la capacidad de uso de las tierras, zonificación biofísica, así como planeación y ordenamiento territorial. Ha colaborado en el módulo "Percepción remota y análisis digital de imágenes", del diplomado en Geomática del CentroGeo, y ha impartido el curso "Ordenamiento territorial y sistemas de información geográfica" en ese mismo centro de investigación. Tiene más de 25 años de experiencia en proyectos generales y semidetallados de suelos, geopedología, zonificación de tierras y análisis fisiográfico. ORCID: https://orcid.org/0000-0003-14767678

Recepción: 21 de febrero de 2018.

Aceptación: 11 de abril de 2018. 